\title{
RECITAL ON MULTICARRIER COMMUNICATIONS: SPACE-TIME CODED VERSUS ADAPTIVE OFDM/MC-CDMA
}

\section{KEYNOTE LECTURE}

\author{
Lajos Hanzo ${ }^{1}$, Lie-Liang Yang, Matthias Münster and Byoung-Jo Choi \\ School of Electronics and Computer Science, \\ University of Southampton, SO17 1BJ, UK. \\ Tel: +44-23-80 593 125, Fax: +44-23-80 594508 \\ Email: $1 \mathrm{~h}^{1} @ e c s . s o t o n . a c . u k$ \\ http: //www-mobile.ecs. soton.ac.uk
}

\section{ABSTRACT}

This overview portrays the evolution of multi-carrier systems from their conception and demonstrates that they are capable of supporting the requirements of future wireless systems of the next generation,

The a novel multiple access scheme based on slow frequency hopping multicarrier direct-sequence code-division multipleaccess (SFH/MC DS-CDMA) is highlighted, which can be rendered compatible with the existing 2nd-generation narrow-band CDMA, and 3rd-generation wideband CDMA mobile communication systems. A RAKE receiver structure with maximum ratio combining is considered and its performance is evaluated over the range of Nakagami multipath fading channels, under the assumption that the receiver has an explicit knowledge of the associated frequency-hopping $(\mathrm{FH})$ patterns invoked.

It is argued furthermore that symbol-by-symbol adaptive Orthogonal Frequency Division Multiplex (OFDM) modems counteract the near instantaneous channel quality variations and hence attain an increased throughput in comparison to their fixed-mode counterparts. By contrast, various diversity techniques, such as Rake receivers and space-time coding, mitigate the channel quality variations in their effort to obtain a reduced BER. This paper investigates a combined system constituted by a constant-power adaptive modem employing spacetime coded diversity techniques in the context of both OFDM and MC-CDMA. The combined system is configured to produce a constant uncoded BER and exhibits virtually error free performance, when a turbo convolutional code is concatenated with a space-time block code. It was found that the advantage of the adaptive modem erodes, as the overall diversity-order increases.

\section{MOTIVATION}

Although the roll-out of the third-generation (3G) systems [1] has been somewhat delayed, the research community turned its attention to the investigation of next-generation multi-carrier transceiver techniques $[2,3,4]$. The next-generation wireless systems are expected to support both variable-rate as well as extremely highbitrate services in a wide range of different propagation environments. Under these propagation conditions it is irrealistic to expect that conventional fixed-mode transceivers might be capable of supporting a time-invariant wireline-like quality of service and hence near-instantaneously adaptive transceiver techniques $[5,6]$ have found their way into the High-Speed Data Packet Access (HSDPA) mode of the 3G systems. Multi-standard operation is also a salient requirement. As it was argued in the context of the generic futureproof system design framework outlined in Chapter I of [2], MultiCarrier (MC) transmission techniques [3, 2, 7], such as Orthogonal Frequancy Division Multiplexing (OFDM) [3] and its frequencydomain spreading aided version, namely MC Code Division MUltiple Access (MC-CDMA) exhibit the highest number of reconfigurable parameters amongst all potential transceivers schemes that may be reconfigured in an effort to satisfy the above-mentioned challenging system requirements. Another attractive relative of this MC transceiver family is Direct Sequence (DS) MC-CDMA [2]. Hence, following a rudimentary introduction to the subject and a brief tour of the $\mathrm{MC}$ transceiver history, this overview article will consider a number of design aspects pertaining to $\mathrm{MC}$ communications.

\section{OFDM BASICS}

In this introductory section we examine OFDM as a means of counteracting the channel-induced linear distortions encountered, when transmitting over a dispersive radio channel. The fundamental principle of orthogonal multiplexing originates from Chang [8], and over the years a number of researchers have investigated this technique $[9,10,11,12,13,14,15,16,17,18,19,20]$. Despite its conceptual elegance, until recently its deployment has been mostly limited to military applications due to implementational difficulties. However, it has recently been adopted as the new European Digital Audio Broadcasting (DAB) standard, and this consumer electronics application underlines its significance as a broadcasting technique $[21,22,23,24,25]$.

In the OFDM scheme of Figure 1 the serial data stream of a traffic channel is passed through a serial-to-parallel convertor which splits the data into a number of parallel channels. The data in each channel is applied to a modulator, such that for $N$ channels there are $N$ modulators whose carrier frequencies are $f_{0}, f_{1}$, ..., $f_{N-1}$. The difference between adjacent channels is $\Delta f$ and the overall bandwidth $W$ of the $N$ modulated carriers is $N \Delta f$.

These $N$ modulated carriers are then combined for the sake of generating the OFDM signal. We may view the serial-to-parallel convertor as applying every $N$ th symbol to a modulator. This has the effect of interleaving the symbols into each modulator, e.g. symbols $S_{0}, S_{N}, S_{2 N}, \ldots$ are applied to the modulator whose carrier frequency is $f_{1}$. At the receiver the received OFDM signal is demultiplexed into $N$ frequency bands, and the $N$ modulated signals are demodulated. The baseband signals are then recombined using a parallel-to-serial convertor.

In the more conventional serial transmission approach [4], the traffic data is applied directly to the modulator transmitting at a carrier frequency positioned at the centre of the transmission band $f_{0}, \ldots, f_{N-1}$, ie at $\left(f_{N-1}+f_{0}\right) / 2$. The modulated signal occupies the entire bandwidth $W$. When the data is transmitted serially, the effect of a deep fade in a mobile channel is to cause a burst of transmission errors, if the fade extends over the duration of several bits. By contrast, during an $\mathrm{N}$-symbol duration period of the conventional serial system, each of the $N$ number of OFDM subchannel modulators carries only one symbol, each of which has an $N$ times longer duration. Hence an identical-duration channel fade would only affect a fraction of the duration of each of the extended-length subcarrier symbols transmitted in parallel. Therefore the OFDM system may be able to recover all of the partially fading-contaminated $N$ subcarrier symbols. Thus, while the serial 


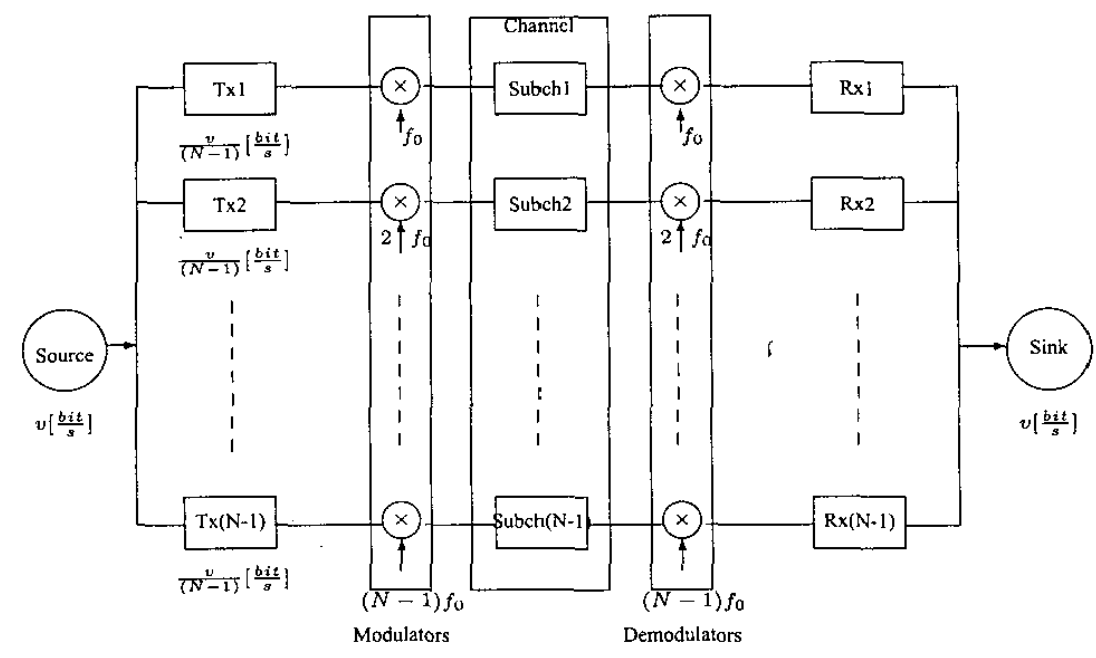

Figure 1: Simplified block diagram of the orthogonal parallel modem

system exhibits an error burst, no errors or few errors may occur using the OFDM approach.

A further advantage of OFDM is that because the symbol period has been increased, the channel's delay spread becomes a significantly shorter fraction of a symbol period than in the serial system, potentially rendering the system less sensitive to channelinduced dispersion, than the conventional serial system.

A disadvantage of the OFDM approach portrayed in Figure 1 is its increased complexity in comparison to a conventional serial modem, which is a consequence of employing $N$ modulators and transmit filters at the transmitter and $N$ demodulators and receive filters at the receiver.

However, as it was shown in Chapter 2 of [3], the associated complexity can be susbtantially reduced by employing the Discrete Fourier Transform (DFT) for modulating all subcarriers in a single step. From a tangible physical perspective this may be explained by arguing that all the OFDM subcarriers are orthogonal complexvalued exponential functions, which have a frequency that is an integer multiple of the basis frequency $f_{0}$, exactly as in case of the complex-valued exponential basis functions of the DFT/IDFT. Hence instead of multiplying each subcarrier individually for example by \pm 1 as in BPSK modulation, the modulation process implies 'transforming' a block of $N$ BPSK symbols in a single step using the IDFT/DFT, yielding a block of $N$ modulated samples, as illustrated mathematically in [3].

When the number of subcarriers is high, the system's complexity may be further reduced by implementing the DFT with the aid of the Fast Fourier transform (FFT), again, as it was shown mathematically in [3].

\section{ADAPTIVE OFDM}

A particularly attractive feature of OFDM systems is that they are capable of operating without a classic channel equaliser, when communicating over dispersive transmission media, such as wireless channels, while conveniently accommodating the time- and frequency-domain channel quality fluctuations of the wireless channel.

Explicitly, the channel SNR variation versus both time and frequency of an indoor wireless channel is shown in a three-dimensional form in Figure 2 versus both time and frequency, which suggests that OFDM constitutes a convenient framework for accommodating the channel quality fluctuations of the wireless channel, as will be briefly augmented below. This channel transfer function was recorded for the channel impulse response of Figure 3, by simply transforming the impulse response to the frequency domain at regular time intervals, while its taps fluctuated according to the Rayleigh distribution.

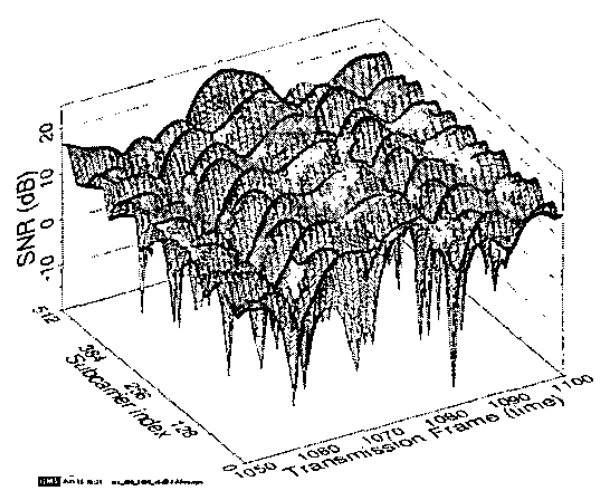

Figure 2: Instantaneous channel SNR for the 512 OFDM subcarriers versus time, for an average channel SNR of $16 \mathrm{~dB}$ over the channel characterised by the Channel Impulse Response (CIR) of Figure 3.

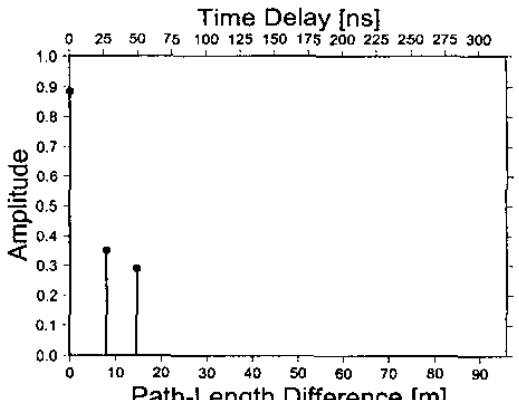

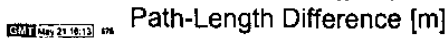

Figure 3: Indoor three-path WATM channel impulse response.

These channel quality fuctuations may be readily accommodated with the aid of sub-band-adaptive modulation as follows. Such an adaptive OFDM (AOFDM) modem is characterised by Figure 4, portraying at the top a contour plot of the above-mentioned wireless channel's signal-to-noise ratio (SNR) fluctuation versus both time and frequency for each OFDM subcarrier. We note at this early stage that these channel quality fluctuations may be mitigated with the aid of frequency-domain channel equalisation, as it was illustrated both graphically as well as mathematically in [3]. 

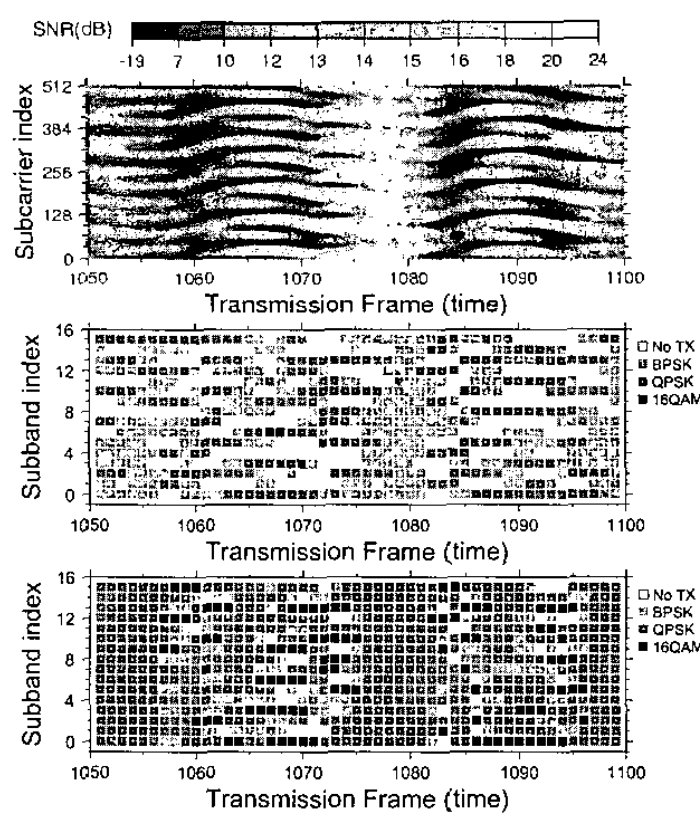

Figure 4: The micro-adaptive nature of the sub-band-adaptive OFDM modem. The top graph is a contour plot of the channel SNR for all 512 subcarriers versus time. The bottom two graphs show the modulation modes chosen for all 16 32-subcarrier sub-bands for the same period of time. The middle graph shows the performance of the $3.4 \mathrm{Mbps}$ sub-band-adaptive modem, which operates at the same bit rate as a fixed BPSK modem. The bottom graph represents the $7.0 \mathrm{Mbps}$ sub-band-adaptive modem, which operated at the same bit rate as a fixed QPSK modem. The average channel SNR was $16 \mathrm{~dB}$.

We will briefly revisit this topic also in this contribution at a later stage.

More specifically, as can be seen in Figure 2, that when the channel is of high quality - as for example in the vicinity of the OFDM symbol index of 1080 - the sub-band-adaptive modem considered here for the sake of illustration has used the same modulation mode, as the identical-throughput conventional fixedrate OFDM modem in all subcarriers, which was 1 bit per symbol (BPS) in this example, as in conventional Binary Phase Shift Keying (BPSK). By contrast, when the channel is hostile - for example, around frame $1060-$ the sub-band-adaptive modem transmitted zero bits per symbol in some sub-bands, corresponding to disabling transmissions in the low-quality sub-bands. In order to compensate for the loss of throughput in this sub-band, a higherorder modulation mode was used in the higher quality sub-bands.

In the centre and bottom subfigures of Figure 4 the modulation mode chosen for each 32-subcarrier sub-band is shown versus time for two different high-speed wireless modems communicating at either 3.4 or $7.0 \mathrm{Mbps}$, respectively, again, corresponding to an average throughput of either 1 or 2 BPS

However, these adaptive transceiver principles are not limited to employment in OFDM transmissions. In recent years the concept of intelligent multi-mode, multimedia transceivers (IMMT) has emerged in the context of a variety of wireless systems [5, $26,27,28,4,29,30]$. The range of various existing solutions that have found favour in already operational standard systems has been summarised in the excellent overview by Nanda et al. [28]. The aim of these adaptive transceivers is to provide mobile users with the best possible compromise amongst a number of contradicting design factors, such as the power consumption of the handheld portable station (PS), robustness against transmission errors, spectral efficiency, teletraffic capacity, audio/video quality and so forth [27].
Another design alternative applicable in the context of OFDM systems is that the channel quality fluctuations observed, for example, in Figure 2 are averaged out with the aid of frequency-domain spreading codes, which leads to the concept of Multi-Carrier Code Division Multiple Access (MC-CDMA). In this scenario typically only a few chips of the spreading code are obliterated by the frequencyselective fading and hence the chances are that the spreading code and its conveyed data may still be recoverable. The advantage of this approach is that in contrast to AOFDM-based communications, in MC-CDMA no channel quality estimation and signalling are required. Therefore, based on the more detailed exposures in [3], OFDM and MC-CDMA will be comparatively studied in Sections 7.2-7.4 of this contribution. We will also consider the employment of Walsh-Hadamard code-based spreading of each subcarrier's signal across the entire OFDM bandwidth, which was found to be an efficient frequency-domain fading counter-measure capable of operating without the employment of adaptive modulation.

A further techique capable of mitigating the channel quality fluctuations of wireless channels is constituted by space-time coding [6], which will also be considered as an attractive anti-fading design option capable of attaining a high diversity gain. Space-time coding employs several transmit and receive antennas for the sake of achieving diversity gain and hence an improved performance.

By contrast, in Part 2 of [3] multiple antennas were employed at the base-station for a different reason, namely for the sake of supporting multiple users, rather than to achieving transmit diversity gain. This is possible, since the users' channel impulse responses (CIR) or channel transfer functions are accurately estimated and hence these channel transfer functions may be viewed as unique user signature sequences, which allow us to recognise and demultiplex the transmissions of the individual users, in a similar fashion to the unique user-specific spreading codes employed in CDMA systems. We note, however, that this technique is only capable of reliably separating the users communicating within the same bandwidth, if their CIRs are sufficiently different. This assumption is typically valid for the uplink, although it may have a limited validity, when the base station receives from mobile stations in its immediate vicinity. By contrast, different techniques have to be invoked for downlink multi-user transmissions. For reasons of space economy, here we restric our discourse on SDMA schemes to a rudimentary discussion of the related research aspects in Sections 5.5 and 5.6.

\section{PILOT-AIDED CHANNEL ESTIMATION}

The simple philosophy of frequency-domain channel estimation is that known pilot-symbols are allocated to the OFDM subcarriers at a regular frequency spacing. The required pilot-spacing is determined by the rate of frequency-domain channel transfer function (FDCHTF) fluctuation versus the frequency axis. More explicitly, these pilot subcarriers have to facilitate adequate sampling of the FDCHTF $H(n)$, requiring that the corresponding sampling frequency is higher than the Nyquist frequency necessitated for the aliasing-free representation of the FDCHTF, as well as for its recovery from these pilot-aided 'Nyquist-rate samples' of the FDCHTF [3]. The frequency-separation between the FDCHTF fades observed in Figure 2 depends on the maximum CIR duration observed for example in Figure 3, since they are Fourier transform pairs. More explicitly, the longer the CIR, the more frequent are the FDCHTF fades and vive versa.

The above-mentioned OFDM symbol-by-symbol based FDCHTF estimation approach may be rendered more efficient, potentially requiring a lower pilot overhead, if the FDCHTF of consecutive OFDM symbols is predicted also as a function of time, resulting in two-dimensional (2D) pilot-aided FDCHTF estimation, as detailed in [3]. As in the context of the FDCHTF estimation versus frequency, the required time-direction pilot-density is also determined by the Nyquist theorem, this time obeying twice the Doppler frequency encountered by the CIR taps, as it is illustrated both graphically as well as mathematically in [3]. 


\section{ORTHOGONAL FREQUENCY DIVISION MULTIPLEXING HISTORY}

\subsection{Early Classic Contributions}

The first OFDM scheme was proposed by Chang in 1966 [8] for dispersive fading channels. During the early years of the evolution of OFDM research the contributions due to the efforts of Weinstein, Peled, Ruiz, Hirosaki, Kolb, Cimini, Schüssler, Preuss, Rückriem, Kalet et al. $[8,9,13,18,23,24,14,15,16,17,19,20,25,31]$ have to be mentioned. As unquestionable proof of its maturity, OFDM was standardised as the European digital audio broadcast (DAB) as well as digital video broadcast (DVB) scheme. It constituted also a credible proposal for the recent third-generation mobile radio standard competition in Europe. Finally, OFDM was recently selected as the high performance local area network's (HIPERLAN) transmission technique as well as becoming part of the IEEE 802.11 Wireless Local Area Network (WLAN) standard.

As it was portrayed in Figure 1, the system's operational principle is that the original bandwidth is divided into a high number of narrow sub-bands, in which the mobile channel can be considered non-dispersive. Hence no channel equaliser is required and instead of implementing a bank of sub-channel modems they can be conveniently implemented with the aid of a single FFT operation, as was shown mathematically in Chapter 2 of [3].

These OFDM systems - often also termed frequency division multiplexing (FDM) or multi-tone systems - have been employed in military applications since the 1960s, for example by Bello [32], Zimmermann [9], Powers and Zimmerman [10], Chang as well as Gibby [12] and others. Saltzberg [11] studied a multi-carrier system employing orthogonal time-staggered Quadrature Amplitude Modulation (O-QAM) of the carriers.

The employment of the discrete Fourier transform (DFT) to replace the banks of sinusoidal generators and the demodulators was suggested by Weinstein and Ebert [ J3] in 1971, which significantly reduces the implementation complexity of OFDM modems. In 1980, Hirosaki [31] suggested an equalisation algorithm in order to suppress both intersymbol and intersubcarrier interference caused by the channel impulse response or timing and frequency errors. Simplified OFDM modem implementations were studied by Peled [14] in 1980, while Hirosaki [15] introduced the DFTbased implementation of Saltzberg's O-QAM OFDM system. From Erlangen University, Kolb [16], Schssler [17], Preuss [19] and Rckriem [20] conducted further research into the application of OFDM. Cimini [18] and Kalet [25] published analytical and early seminal experimental results on the performance of OFDM modems in mobile communications channels.

More recent advances in OFDM transmission were presented in the impressive state-of-the-art collection of works edited by Fazel and Fettweis [33], including the research by Fettweis et al. at Dresden University, Rohling et al. at Braunschweig University, Vandendorp at Loeven University, Huber et al. at Erlangen University, Lindner $e t a l$. at Ulm University, Kammeyer et al. at Bremen University and Meyr et al. $[34,35]$ at Aachen University, but the individual contributions are too numerous to mention. Important recent references are the books by van Nee and Prasad [36] as well as by Vandenameele, van der Perre and Engels [37].

While OFDM transmission over mobile communications channels can alleviate the problem of multipath propagation, recent research efforts have focused on solving a set of inherent difficulties regarding OFDM, namely the peak-to-mean power ratio, time and frequency synchronisation, and on mitigating the effects of the frequency selective fading channel. These issues are addressed below with reference to the literature, while a more in-depth treatment is given throughout the book.

\subsection{Peak-to-mean Power Ratio}

It is plausible that the OFDM signal - which is the superposition of a high number of modulated sub-channel signals - may exhibit a high instantaneous signal peak with respect to the average signal level. Furthermore, large signal amplitude swings are encountered, when the time domain signal traverses from a low instantaneous power waveform to a high power waveform, which may results in a high out-of-band (OOB) harmonic distortion power, unless the transmitter's power amplifier exhibits an extremely high linearity across the entire signal level range. This then potentially contaminates the adjacent channels with adjacent channel interference. Practical amplifiers exhibit a finite amplitude range, in which they can be considered almost linear. In order to prevent severe clipping of the high OFDM signal peaks - which is the main source of OOB emissions - the power amplifier must not be driven to saturation and hence they are typically operated with a certain so-called back-off, creating a certain "head room" for the signal peaks, which reduces the risk of amplifier saturation and $O O B$ emission. Two different families of solutions have been suggested in the literature, in order to mitigate these problems, either reducing the peak-to-mean power ratio, or improving the amplification stage of the transmitter.

More explicitly, Shepherd [38], Jones [39], and Wulich [40] have suggested different coding techniques which aim to minimise the peak power of the OFDM signal by employing different data encoding schemes before modulation, with the philosophy of choosing block codes whose legitimate code words exhibit low so-called crest factors or peak-to-mean power envelope fluctuation. Müller [41], Pauli [42], May [43] and Wulich [44] suggested different algorithms for post-processing the time domain OFDM signal prior to amplification, while Schmidt and Kammeyer [45] employed adaptive subcarrier allocation in order to reduce the crest factor. Dinis and Gusmo $[46,47,48]$ researched the use of two-branch amplifiers, while the clustered OFDM technique introduced by Daneshrad, Cimini and Carloni [49] operates with a set of parallel partial FFT processors with associated transmitting chains. OFDM systems with increased robustness to non-linear distortion have been proposed by Okada, Nishijima and Komaki [50] as well as by Dinis and Gusmo [51]. These aspects of OFDM transmissions were treated in substantial depth in Part 2 of [3].

\subsection{Synchronisation}

Time and frequency synchronisation between the transmitter and receiver are of crucial importance as regards the performance of an OFDM link $[52,53]$. A wide variety of techniques have been proposed for estimating and correcting both timing and carrier frequency offsets at the OFDM receiver. Rough timing and frequency acquisition algorithms relying on known pilot symbols or pilot tones embedded into the OFDM symbols have been suggested by Claen [34], Warner [54], Sari [55], Moose [56], as well as Brninghaus and Rohling [57]. Fine frequency and timing tracking algorithms exploiting the OFDM signal's cyclic extension were published by Moose [56], Daffara [58] and Sandell [59]. OFDM synchronisation issues are the subject of Chapter 5 in [3].

\subsection{OFDM/CDMA}

Combining multi-carrier OFDM transmissions with code division multiple access (CDMA) allows us to exploit the wideband channel's inherent frequency diversity by spreading each symbol across multiple subcarriers. This technique has been pioneered by Yee, Linnartz and Fettweis [60], by Chouly, Brajal and Jourdan [61], as well as by Fettweis, Bahai and Anvari [62]. Fazel and Papke [63] investigated the employment of convolutional coding in conjunction with OFDM/CDMA. Prasad and Hara [64] compared various methods of combining the two techniques, identifying three different structures, namely multi-carrier CDMA (MC-CDMA), multi-carrier direct sequence CDMA (MC-DS-CDMA) and multitone CDMA (MT-CDMA). Like non-spread OFDM transmission, OFDM/CDMA methods suffer from high peak-to-mean power ratios, which are dependent on the frequency domain spreading scheme, as investigated by Choi, Kuan and Hanzo [65] and in Part 2 of [3].

\subsection{Decision-Directed Channel Estimation}

In recent years numerous research contributions have appeared on the topic of channel transfer function estimation techniques de- 


\begin{tabular}{|c|c|c|}
\hline Y̌ear & Author & Contribution \\
\hline 91 & Höher [66] & $\begin{array}{l}\text { Cascaded 1D-FIR channel transfer factor interpolation was carried out in the frequency-and time- } \\
\text { direction for frequency-domain PSAM. }\end{array}$ \\
\hline 93 & $\begin{array}{l}\text { Chow, Cioffi and Bing- } \\
\text { ham [67] }\end{array}$ & $\begin{array}{l}\text { Subcarrier-by-subcarrier-based LMS-related channel transfer factor equalisation techniques were } \\
\text { employed. }\end{array}$ \\
\hline 994 & $\begin{array}{l}\text { Wilson, Khayata and } \\
\text { Cioff }[68]\end{array}$ & Linear channel transfer factor filtering was invoked in the time-direction for DDCE. \\
\hline 95 & $\begin{array}{l}\text { van de Beek, Edfors, } \\
\text { Sandell, Wilson and } \\
\text { Börjesson [69] }\end{array}$ & $\begin{array}{l}\text { DFT-aided CIR-related domain Wiener filter-based noise reduction was advocated for DDCE. The } \\
\text { effects of leakage in the context of non-sample-spaced CIRs were analysed. }\end{array}$ \\
\hline \multirow[t]{3}{*}{96} & $\begin{array}{l}\text { Edfors, Sandell, van } \\
\text { de Beek, Wilson and } \\
\text { Börjesson[70] }\end{array}$ & SVD-aided CIR-related domain Wiener filter-based noise reduction was introduced for DDCE. \\
\hline & $\begin{array}{l}\text { Frenger and } \\
\text { Svensson }[71]\end{array}$ & MMSE-based frequency-domain channel transfer factor prediction was proposed for DDCE. \\
\hline & $\begin{array}{l}\text { Mignone and Morello } \\
{[72]}\end{array}$ & FEC was invoked for improving the DDCE's remodulated reference. \\
\hline \multirow[t]{2}{*}{97} & $\begin{array}{l}\text { Tufvesson and Maseng } \\
\text { [73] }\end{array}$ & $\begin{array}{l}\text { An analysis of various pilot patterns employed in frequency-domain PSAM was provided in terms } \\
\text { of the system's BER for different Doppler frequencies. Kalman filter-aided channel transfer factor } \\
\text { estimation was used. }\end{array}$ \\
\hline & $\begin{array}{l}\text { Höher, Kaiser and } \\
\text { Robertson }[74,75]\end{array}$ & $\begin{array}{l}\text { Cascaded ID-FIR Wiener filter channel interpolation was utilised in the context of 2D-pilot pattern- } \\
\text { aided PSAM }\end{array}$ \\
\hline \multirow[t]{4}{*}{98} & $\begin{array}{l}\mathrm{Li}, \mathrm{Cimini} \text { and } \\
\text { Sollenberger [76] }\end{array}$ & $\begin{array}{l}\text { An SVD-aided CIR-related domain Wiener filter-based noise reduction was achieved by employing } \\
\text { CIR-related tap estimation filtering in the time-direction. }\end{array}$ \\
\hline & $\begin{array}{l}\text { Edfors, Sandell, } \\
\text { van de Beek, Wilson } \\
\text { and Börjesson [77] }\end{array}$ & $\begin{array}{l}\text { A detailed analysis of SVD-aided CIR-related domain Wiener filter-based noise reduction was pro- } \\
\text { vided for DDCE, which expanded the results of [70]. }\end{array}$ \\
\hline & $\begin{array}{l}\text { Tufvesson, Faulkner } \\
\text { and Maseng [78] }\end{array}$ & $\begin{array}{l}\text { Wiener filter-aided frequency domain channel transfer factor prediction-assisted pre-equalisation } \\
\text { was studied. }\end{array}$ \\
\hline & $\begin{array}{l}\text { Itami, Kuwabara, } \\
\text { Yamashita, Ohta and } \\
\text { Itoh [79] }\end{array}$ & $\begin{array}{l}\text { Parametric finite-tap CIR model-based channel estimation was employed for frequency domain } \\
\text { PSAM. }\end{array}$ \\
\hline
\end{tabular}

Table 1: Contributions to channel transfer factor estimation for single-transmit antenna-assisted OFDM $\left(\mathrm{Hanzo}^{1}\right.$, Münster, Choi and Keller [3].

\begin{tabular}{|c|c|c|}
\hline Year & Author & Contribution \\
\hline \multirow[t]{2}{*}{99} & $\begin{array}{l}\text { Al-Susa and } \\
\text { Ormondroyd [80] }\end{array}$ & $\begin{array}{l}\text { DFT-aided Burg algorithm-assisted adaptive CIR-related tap prediction filtering was employed for } \\
\text { DDCE. }\end{array}$ \\
\hline & $\begin{array}{l}\text { Yang, Letaief, Cheng } \\
\text { and Cao [81] }\end{array}$ & Parametric, ESPRIT-assisted channel estimation was employed for frequency domain PSAM. \\
\hline 00 & $\mathrm{Li}[82]$ & $\begin{array}{l}\text { Robust 2D frequency domain Wiener filtering was suggested for employment in frequency domain } \\
\text { PSAM using 2D pilot patterns. }\end{array}$ \\
\hline \multirow[t]{7}{*}{01} & $\begin{array}{l}\text { Yang, Letaief, Cheng } \\
\text { and Cao [83] }\end{array}$ & $\begin{array}{l}\text { Detailed discussions of parametric, ESPRIT-assisted channel estimation were provided in the con- } \\
\text { text of frequency domain PSAM [81]. }\end{array}$ \\
\hline & $\begin{array}{l}\text { Zhou and Giannakis } \\
\text { [84] }\end{array}$ & Finite alphabet-based channel transfer factor estimation was proposed. \\
\hline & Wang and Liu [85] & Polynomial frequency domain channel transfer factor interpolation was contrived. \\
\hline & $\begin{array}{l}\text { Yang, Cao and Letaief } \\
{[86]}\end{array}$ & $\begin{array}{l}\text { DFT-aided CIR-related domain one-tap Wiener filter-based noise reduction was investigated, which } \\
\text { is supported by variable frequency domain Hanning windowing. }\end{array}$ \\
\hline & Lu and Wang [87] & A Bayesian blind turbo receiver was contrived for coded OFDM systems. \\
\hline & $\begin{array}{l}\mathrm{Li} \text { and Sollenberger } \\
{[88]}\end{array}$ & Various transforms were suggested for CIR-related tap estimation filtering-assisted DDCE. \\
\hline & $\begin{array}{l}\text { Moreili and Mengali } \\
{[89]}\end{array}$ & $\begin{array}{l}\text { LS- and MMSE-based channel transfer factor estimators were compared in the context of frequency } \\
\text { domain PSAM. }\end{array}$ \\
\hline \multirow[t]{2}{*}{02} & Chang and $\mathrm{Su}[90]$ & $\begin{array}{l}\text { Parametric quadrature surface-based frequency domain channel transfer factor interpolation was } \\
\text { studied for PSAM. }\end{array}$ \\
\hline & Necker and Stüber [91] & $\begin{array}{l}\text { Totally blind channel transfer factor estimation based on the finite alphabet property of PSK signals } \\
\text { was investigated. }\end{array}$ \\
\hline
\end{tabular}

Table 2: Contributions to channel transfer factor estimation for single-transmit antenna-assisted OFDM, (C)Hanzo ${ }^{1}$, Münster, Choi and Keller [3].

signed for employment in single-user, single transmit antenna-assisted OFDM scenarios, since the availability of an accurate channel transfer function estimate is one of the prerequisites for coherent symbol detection with an OFDM receiver. The techniques proposed in the literature can be classified as pilot-assisted, decision-directed (DD)

and blind channel estimation (CE) methods.

In the context of pilot-assisted channel transfer function estimation a subset of the available subcarriers is dedicated to the transmission of specific pilot symbols known to the receiver, which are used for "sampling" the desired channel transfer function. Based 
on these samples of the frequency domain transfer function, the well-known process of interpolation is used for generating a transfer function estimate for each subcarrier residing between the pilots. This is achieved at the cost of a reduction in the number of useful subcarriers available for data transmission. The family of pilot-assisted channel estimation techniques was investigated for example by Chang and Su [90], Höher [66,74,75], Itami et al. [79], Li [82], Tufvesson and Maseng [73], Wang and Liu [85], as well as Yang $e t$ al. $[81,92,86]$.

By contrast, in the context of Decision-Directed Channel Estimation (DDCE) all the sliced and remodulated subcarrier data symbols are considered as pilots. In the absence of symbol errors and also depending on the rate of channel fluctuation, it was found that accurate channel transfer function estimates can be obtained, which often are of better quality, in terms of the channel transfer function estimator's mean-square error (MSE), than the estimates offered by pilot-assisted schemes. This is because the latter arrangements usually invoke relatively sparse pilot patterns.

The family of decision-directed channel estimation techniques was investigated for example by van de Beek et al. [69], Edfors et al. [70, 77], Li et al. [76], Li [88], Mignone and Morello [72], Al-Susa and

Ormondroyd [80], Frenger and Svensson [71], as well as Wilson et al. [68]. Furthermore, the family of blind channnel estimation techniques was studied by Lu and Wang [87], Necker and Stüber [91], as well as by Zhou and Giannakis [84]. The various contributions have been summarized in Tables 1 and 2 .

In order to render the various DDCE techniques more amenable to use in scenarios associated with a relatively high rate of channel variation expressed in terms of the OFDM symbol normalized Doppler frequency, linear prediction techniques well known from the speech coding literature $[93,94]$ can be invoked. To elaborate a little further, we will substitute the CIR-related tap estimation filter - which is part of the two-dimensional channel transfer function estimator proposed in [76] - by a CIR-related tap prediction filter. The employment of this CIR-related tap prediction filter enables a more accurate estimation of the channel transfer function encountered during the forthcoming transmission time slot and thus potentially enhances the performance of the channel estimator. We will be following the general concepts described by DuelHallen et al. [95] and the ideas presented by Frenger and Svensson [71], where frequency domain prediction filter-assisted DDCE was proposed. Furthermore, we should mention the contributions of Tufvesson et al. $[78,96]$, where a prediction filter-assisted frequency domain pre-equalisation scheme was discussed in the context of OFDM. In a further contribution by Al-Susa and Ormondroyd [80], adaptive prediction filter-assisted DDCE designed for OFDM has been proposed upon invoking techniques known from speech coding, such as the Levinson-Durbin algorithm or the Burg algorithm $[93,97,98]$ in order to determine the predictor coefficients.

In contrast to the above-mentioned single-user OFDM scenarios, in a multi-user OFDM scenario the signal received by each antenna is constituted by the superposition of the signal contributions associated with the different users or transmit antennas. Note that in terms of the multiple-input multiple-output (MIMO) structure of the channel the multi-user single-transmit antenna scenario is equivalent, for example, to a single-user space-time coded (STC) scenario using multiple transmit antennas. For the latter a Least-Squares (LS) error channel estimator was proposed by $\mathrm{Li} e t$ al. [99], which aims at recovering the different transmit antennas' channel transfer functions on the basis of the output signal of a specific reception antenna element and by also capitalising on the remodulated received symbols associated with the different users. The performance of this estimator was found to be limited in terms of the mean-square estimation error in scenarios, where the product of the number of transmit antennas and the number of CIR taps to be estimated per transmit antenna approaches the total number of subcarriers hosted by an OFDM symbol. As a design alternative, in [100] a DDCE was proposed by Jeon et al. for a space-time coded OFDM scenario of two transmit antennas and two receive antennas.
Specifically, the channel transfer function' associated with each transmit-receive antenna pair was estimated on the basis of the output signal of the specific receive antenna upon subtracting the interfering signal contributions associated with the remaining transmit antennas. These interference contributions were estimated by capitalising on the knowledge of the channel transfer functions of all interfering transmit antennas predicted during the $(n-1)$-th OFDM symbol period for the $n$-th OFDM symbol, also invoking the corresponding remodulated symbols associated with the $n$-th OFDM symbol. To elaborate further, the difference between the subtraction-based channel transfer function estimator of [100] and the LS estimator proposed by Li et al. in [99] is that in the former the channel transfer functions predicted during the previous, i.e. the $(n-1)$-th OFDM symbol period for the current, i.e. the $n$-th OFDM symbol are employed for both symbol detection as well as for obtaining an updated channel estimate for employment during the $(n+1)$-th OFDM symbol period. In the approach advocated in [100] the subtraction of the different transmit antennas' interfering signals is performed in the frequency domain.

By contrast, in [101] a similar technique was proposed by $\mathrm{Li}$ with the aim of simplifying the DDCE approach of [99], which operates in the time domain. A prerequisite for the operation of this parallel interference cancellation (PIC)-assisted DDCE is the availability of a reliable estimate of the various channel transfer functions for the current OFDM symbol, which are employed in the cancellation process in order to obtain updated channel transfer function estimates for the demodulation of the next OFDM symbol. In order to compensate for the channel's variation as a function of the OFDM symbol index, linear prediction techniques can be employed, as it was also proposed for example in [101]. However, due to the estimator's recursive structure, determining the optimum predictor coefficients is not as straightforward as for the transversal FIR filter-assisted predictor of single-user DDCE, both of which are detailed in [3].

A comprehensive overview of further publications on channel transfer factor estimation for OFDM systems supported by multiple transmit antennas is provided in Table 3 .

\subsection{Uplink Detection Techniques for Multi-User SDMA-OFDM}

Combining adaptive antenna-aided techniques with OFDM transmissions was shown to be advantageous [3], for example in the context of suppressing co-channel interference in cellular communications systems. Amongst others, Li, Cimini and Sollenberger [137, 138, 139], Kim, Choi and Cho [140], Lin, Cimini and Chuang [141] as well as Mnster $e t$ al. [142] have investigated algorithms designed for multi-user channel estimation and interference suppression.

The related family of Space-Division-Multiple-Access (SDMA) communication systems has recently drawn wide reseach interests [3]. In these systems the $L$ different users' transmitted signals are separated at the base-station (BS) with the aid of their unique, user-specific spatial signature, which is constituted by the $P$-element vector of channel transfer factors between the users' single transmit antenna and the $P$ different receiver antenna elements at the BS, upon assuming flat-fading channel conditions such as those often experienced in the context of each of the OFDM subcarriers.

A whole host of multi-user detection (MUD) techniques known from Code Division Multiple Access (CDMA) communications lend themselves also to an application in the context of SDMAOFDM on a per-subcarrier basis [3]. Some of these techniques are the Least-Squares (LS) $[143,121,127,135]$, Minimum MeanSquare Error (MMSE) $[143,144,114,118,125,113,115,116$ $145,121,129]$, Successive Interference Cancellation (SIC) [143, $112,117,125,145,121,127,132,134,136]$, Parallel Interference Cancellation (PIC) $[143,133]$ and Maximum Likelihood (ML) detection $[143,125,145,120,122,123,124,126,128,131]$. A comprehensive overview of recent publications on MUD techniques for

'In the context of the OFDM system the set of $K$ different subcarriers' channel transfer factors is referred to as the channel transfer function, or simply as the channel. 


\begin{tabular}{|c|c|c|}
\hline Year & Author & Contribution \\
\hline 99 & $\begin{array}{l}\mathrm{Li}, \quad \text { Seshadri and } \\
\text { Ariyavisitakul [99] }\end{array}$ & $\begin{array}{l}\text { The LS-assisted DDCE proposed exploits the cross-correlation properties of the transmitted sub- } \\
\text { carrier symbol sequences. }\end{array}$ \\
\hline \multirow[t]{2}{*}{00} & $\begin{array}{l}\text { Jeon, Paik and Cho } \\
{[100]}\end{array}$ & $\begin{array}{l}\text { Frequency-domain PIC-assisted DDCE is studied, which exploits the channel's slow variation ver- } \\
\text { sus time. }\end{array}$ \\
\hline & $\mathrm{Li}[101]$ & $\begin{array}{l}\text { Time-domain PIC-assisted DDCE is investigated as a simplification of the LS-assisted DDCE of } \\
\text { [99]. Optimum training sequences are proposed for the LS-assisted DDCE of [99]. }\end{array}$ \\
\hline \multirow[t]{5}{*}{01} & Mody and Stüber [102] & $\begin{array}{l}\text { Channel transfer factor estimation designed for frequency-domain PSAM based on CIR-related } \\
\text { domain filtering is studied. }\end{array}$ \\
\hline & Gong and Letaief [103] & $\begin{array}{l}\text { MMSE-assisted DDCE is advocated which represents an extension of the LS-assisted DDCE of } \\
\text { [103]. The MMSE-assisted DDCE is shown to be practical in the context of transmitting con- } \\
\text { secutive training blocks. Additionally, a low-rank approximation of the MMSE-assisted DDCE is } \\
\text { considered. }\end{array}$ \\
\hline & $\begin{array}{l}\text { Jeon, Paik and Cho } \\
\text { [104] }\end{array}$ & 2D MMSE-based channel estimation is proposed for frequency-domain PSAM. \\
\hline & $\begin{array}{l}\text { Vook and Thomas } \\
{[105]}\end{array}$ & $\begin{array}{l}\text { 2D MMSE based channel estimation is invoked for frequency domain PSAM. A complexity reduc- } \\
\text { tion is achieved by CIR-related domain-based processing. }\end{array}$ \\
\hline & $\begin{array}{l}\mathrm{Xie} \text { and Georghiades } \\
{[106]}\end{array}$ & Expectation maximization (EM) based channel transfer factor estimation approach for DDCE. \\
\hline \multirow[t]{4}{*}{02} & $\mathrm{Li}[107]$ & $\begin{array}{l}\text { A more detailed discussion on time-domain PIC-assisted DDCE is provided and optimum training } \\
\text { sequences are proposed [101]. }\end{array}$ \\
\hline & $\begin{array}{l}\text { Bölcskei, Heath and } \\
\text { Paulraj [108] }\end{array}$ & $\begin{array}{l}\text { Blind channel identification and equalisation using second-order cyclostationary statistics as well } \\
\text { as antenna precoding were studied. }\end{array}$ \\
\hline & $\begin{array}{l}\text { Minn, Kim and } \\
\text { Bhargava [109] }\end{array}$ & $\begin{array}{l}\text { A reduced complexity version of the LS-assisted DDCE of [99] is introduced, based on exploiting } \\
\text { the channel's correlation in the frequency-direction, as opposed to invoking the simplified scheme } \\
\text { of [107], which exploits the channel's correlation in the time-direction. A similar approach was } \\
\text { suggested by Slimane [110] for the specific case of two transmit antennas. }\end{array}$ \\
\hline & $\begin{array}{l}\text { Komninakis, } \\
\text { Fragouli, Sayed } \\
\text { Wesel [111] }\end{array}$ & $\begin{array}{l}\text { Fading channel tracking and equalisation were proposed for employment in MIMO systems assisted } \\
\text { by Kalman estimation and channel prediction. }\end{array}$ \\
\hline
\end{tabular}

Table 3: Contributions on channel transfer factor estimation for multiple-transmit antenna assisted $\mathrm{OFDM}_{(\mathrm{CHanzo}}{ }^{1}$, Münster, Choi and Keller [3].

\begin{tabular}{|c|c|c|}
\hline Year & Author & Contribution \\
\hline 96 & Foschini $[112]$ & The concept of the BLAST architecture was introduced. \\
\hline \multirow[t]{4}{*}{98} & Vook and Baum [113] & SMI-assisted MMSE combining was invoked on an OFDM subcarrier basis. \\
\hline & Wang and Poor [114] & $\begin{array}{l}\text { Robust sub-space-based weight vector calculation and tracking were employed for co-channel in- } \\
\text { terference suppression, as an improvement of the SMI-algorithm. }\end{array}$ \\
\hline & $\begin{array}{l}\text { Wong, Cheng, Letaief } \\
\text { and Murch [115] }\end{array}$ & $\begin{array}{l}\text { Optimization of an OFDM system was reported in the context of multiple transmit and receive an- } \\
\text { tennas upon invoking the maximum SINR criterion. The computational was reduced by exploiting } \\
\text { the channel's correlation in the frequency direction. }\end{array}$ \\
\hline & $\begin{array}{l}\mathrm{Li} \text { and Sollenberger } \\
{[116]}\end{array}$ & $\begin{array}{l}\text { Tracking of the channel correlation matrix' entries was suggested in the context of SMI-assisted } \\
\text { MMSE combining for multiple receiver antenna assisted OFDM, by capitalizing on the principles } \\
\text { of [76]. }\end{array}$ \\
\hline \multirow[t]{4}{*}{99} & $\begin{array}{l}\text { Golden, Foschini, } \\
\text { Valenzuela and Wolni- } \\
\text { ansky [117] }\end{array}$ & The SIC detection-assisted V-BLAST algorithm was introduced. \\
\hline & $\begin{array}{l}\mathrm{Li} \text { and Sollenberger } \\
{[118]}\end{array}$ & The system introduced in [116] was further detailed. \\
\hline & $\begin{array}{l}\text { Vandenameele, Van der } \\
\text { Perre, Engels and de } \\
\text { Man [119] }\end{array}$ & $\begin{array}{l}\text { A comparative study of different SDMA detection techniques, namely that of MMSE, SIC and } \\
\text { ML detection was provided. Further improvements of SIC detection were suggested by adaptively } \\
\text { tracking multiple symbol decisions at each detection node. }\end{array}$ \\
\hline & Speth and Senst $[120]$ & $\begin{array}{l}\text { Soft-bit generation techniques were proposed for MLSE in the context of a coded SDMA-OFDM } \\
\text { system. }\end{array}$ \\
\hline \multirow[t]{3}{*}{00} & $\begin{array}{l}\text { Sweatman, Thompson, } \\
\text { Mulgrew and Grant } \\
\text { [121] }\end{array}$ & $\begin{array}{l}\text { Comparisons of various detection algorithms including LS, MMSE, D-BLAST and V-BLAST (SIC } \\
\text { detection) were carried out. }\end{array}$ \\
\hline & $\begin{array}{l}\text { van Nee, van Zelst and } \\
\text { Awater }[122,123,124]\end{array}$ & $\begin{array}{l}\text { The evaluation of ML detection in the context of a Space-Division Multiplexing (SDM) system was } \\
\text { provided, considering various simplified ML detection techniques. }\end{array}$ \\
\hline & $\begin{array}{l}\text { Vandenameele, Van } \\
\text { der Perre, Engels, } \\
\text { Gyselinckx and de Man } \\
{[125]}\end{array}$ & More detailed discussions were provided on the topics of [119]. \\
\hline
\end{tabular}

Table 4: Contributions on multi-user detection techniques designed for multiple transmit antenna assisted OFDM systems $\left(\mathrm{Hanzo}^{1}\right.$, Münster, Choi and Keller [3]. 


\begin{tabular}{|c|c|c|}
\hline Year & Author & Contribution \\
\hline 00 & $\begin{array}{l}\text { Li, Huang, Lozano and } \\
\text { Foschini [126] }\end{array}$ & $\begin{array}{l}\text { Reduced complexity ML detection was proposed for multiple transmit antenna systems employing } \\
\text { adaptive antenna grouping and multi-step reduced-complexity detection. }\end{array}$ \\
\hline \multirow[t]{8}{*}{$\overline{01}$} & $\begin{array}{l}\text { Degen, Walke, } \\
\text { Lecomte and Rem- } \\
\text { bold [127] }\end{array}$ & $\begin{array}{l}\text { An overview of various adaptive MIMO techniques was provided. Specifically, pre-distortion was } \\
\text { employed at the transmitter, as well as LS- or BLAST detection were used at the receiver or balanced } \\
\text { equalisation was invoked at both the transmitter and receiver. }\end{array}$ \\
\hline & Zhu and Murch [128] & A tight upper bound on the SER performance of ML detection was derived. \\
\hline & $\begin{array}{l}\mathrm{Li} \text {, Letaief, Cheng and } \\
\text { Cao [129] }\end{array}$ & $\begin{array}{l}\text { Joint adaptive power control and detection were investigated in the context of an OFDM/SDMA } \\
\text { system, based on the approach of Farrokhi et al. [130]. }\end{array}$ \\
\hline & $\begin{array}{l}\text { van Zelst, van Nee and } \\
\text { Awater [131] }\end{array}$ & Iterative decoding was proposed for the BLAST system following the turbo principle. \\
\hline & $\begin{array}{l}\text { Benjebbour, Murata } \\
\text { and Yoshida [132] }\end{array}$ & $\begin{array}{l}\text { The performance of V-BLAST or SIC detection was studied in the context of backward iterative } \\
\text { cancellation scheme employed after the conventional forward cancellation stage. }\end{array}$ \\
\hline & $\begin{array}{l}\text { Sellathurai and Haykin } \\
{[133]}\end{array}$ & $\begin{array}{l}\text { A simplified D-BLAST was proposed, which used iterative FIC capitalizing on the extrinsic soft-bit } \\
\text { information provided by the FEC scheme used. }\end{array}$ \\
\hline & $\begin{array}{l}\text { Bhargave, Figueiredo } \\
\text { and Eltoft [134] }\end{array}$ & $\begin{array}{l}\text { A detection algorithm was suggested, which followed the concepts of V-BLAST or SIC. However, } \\
\text { multiple symbols states are tracked from each detection stage, where - in contrast to [125] - an } \\
\text { intermediate decision is made at intermediate detection stages. }\end{array}$ \\
\hline & $\begin{array}{l}\text { Thoen, Deneire, Van } \\
\text { der Perre and Engels } \\
{[135]}\end{array}$ & $\begin{array}{l}\text { A constrained LS detector was proposed for OFDM/SDMA, which was based on exploiting the } \\
\text { constant modulus property of PSK signals. }\end{array}$ \\
\hline 02 & $\mathrm{Li}$ and Luo $[1 \overline{36}]$ & $\begin{array}{l}\text { The block error probability of optimally ordered V-BLAST was studied. Furthermore, the block } \\
\text { error probability is also investigated for the case of tracking multiple parallel symbol decisions } \\
\text { from the first detection stage, following an approach similar to that of [125]. }\end{array}$ \\
\hline
\end{tabular}

Table 5: Contributions on detection techniques for MIMO systems and for multiple transmit antenna assisted OFDM systems (CHanzo ${ }^{1}$, Münster, Choi and Keller [3].

MIMO systems is given in Tables 4 and 5 .

\subsection{OFDM Applications}

Due to their implementational complexity, OFDM applications have been scarce until quite recently. Recently, however, OFDM has been adopted as the new European digital audio broadcasting (DAB) standard $[21,22,23,24,146]$ as well as for the terrestrial digita] video broadcasting (DVB) system $[55,147]$.

For fixed-wire applications, OFDM is employed in the asynchronous digital subscriber line (ADSL) and high-bit-rate digital subscriber line (HDSL) systems $[148,149,150,151]$ and it has also been suggested for power line communications systems $[152,153]$ due to its resilience to time dispersive channels and narrow band interferers.

Various OFDM applications were also studied within the 4th6th European Framework Programme [154]. For example, an OFDMbased $155 \mathrm{Mbps}$ wireless asynchronous transfer mode (WATM) network was designed by the so-called MEDIAN project in [155, $156,157,158]$, while the Magic WAND group $[159,160]$ developed a wireless local area network (LAN). Hallmann and Rohling [16 presented a range of different OFDM systems that were applicable to the European Telecommunications Standardisation Institute's (ETSI) recent personal communications oriented air interface concept [162]

\section{SLOW FREQUENCY-HOPPED MC DS-CDMA}

\subsection{The Transmitted Signal}

The model of the transmitter and the multiple access channel is depicted in Fig. 5. Each subcarrier of the $K$ users in the system is assigned a randomly generated signature sequence, which produce spread, wideband signals. In the figure, $\mathrm{C}\left(Q, U_{k}\right)$ represents a constant-weight code of user $k$ with $U_{k}$ number of ' I's out of $Q$, i.e., the weight of $\mathrm{C}\left(Q, U_{k}\right)$ is $U_{k}$. This code is read from a socalled constant-weight code book, which represents the frequencyhopping patterns. Theoretically, the size of the constant-weight code book is $\left(\begin{array}{c}Q \\ U_{k}\end{array}\right)=Q ! / U_{k} !\left(Q-U_{k}\right) !$ and the constant-weight code $\mathrm{C}\left(Q, U_{K}\right)$ plays two different roles. Its first role is that its weight - namely $U_{k}$ - determines the number of subcarriers activated, while its second function is that the positions of the $U_{k}$ number of binary " 1 's determine the selection of a set of $U_{k}$ num-

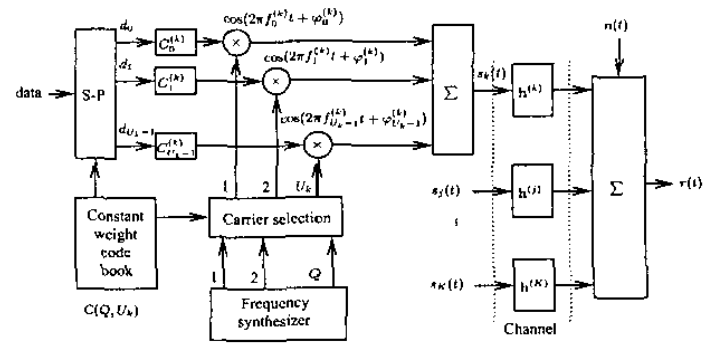

Figure 5: Transmitter and channel block diagram of the frequencyhopping multicarrier DS-CDMA systems.

ber of subcarrier frequencies from the $Q$ number of outputs of the frequency synthesizer.

At the transmitter of the $k$ th user in Fig. 5 the bit stream having a bit duration of $T_{b}$ is first serial-to-parallel converted, yielding $U_{k}$ parallel streams, which is controlled by the constant-weight code $\mathrm{C}\left(Q, U_{k}\right)$. Let the new bit duration of each parallel stream be expressed as $T$, which can be $T=U_{k} T_{b}$ or $T=T_{b}$, depending on the objectives of the system design, as it will be augmented during our further discourse. For example, if the design aims to mitigate the inter-symbol-interference (ISI) in a high-bit rate transmission scheme, a high bit duration is required, and hence $T=U_{k} T_{b}$ can be employed. However, if the design aims to support multiple information rates, a constant bit duration can be employed, and multi-rate transmissions are implemented by employing a different number of subcarriers. Theoretically, $Q$ number of different information rates can be supported by changing the weight of the code $\mathrm{C}\left(Q, U_{k}\right)$. As seen in Fig. 5, after serial-to-parallel conversion each stream is direct-sequence (DS) spread, in order to form the spread, wideband signal, and this spread signal then modulates one of the selected subcarriers. Finally, the transmitted signal of the $k$ th user can be expressed as:

$$
s_{k}(t)=\sum_{u_{k}=0}^{U_{k}-1} \sqrt{2 P} d_{u_{k}}^{(k)}(t) c_{u_{k}}^{(k)}(t) \cos \left(2 \pi f_{u_{k}}^{(k)} t+\varphi_{u_{k}}^{(k)}\right),
$$

where $P$ represents the transmitted power per subcarrier, while $U_{k}$ indicates the weight of the constant-weight code currently em- 
ployed by the $k$ th user. Furthermore, $\left\{d_{u_{k}}^{(k)}(t)\right\},\left\{c_{u_{k}}^{(k)}(t)\right\},\left\{f_{u_{k}}^{(k)}\right\}$ and $\left\{\varphi_{u_{k}}^{(k)}\right\}$ represent the current data stream's waveforms, the DS spreading waveforms, the subcarrier frequency set and the phase angles introduced in the carrier modulation process. Let $T_{c}$ be the chip duration of the DS spreading waveforms and $N=T_{b} / T_{\mathrm{c}}$. Then the processing gain of $N_{P}=T / T_{c}$ equals to $U_{k} N$ or $N$, depending on the system's objectives, as discussed previously. Furthermore, we assume that the frequency hopping duration is $T_{h}$, and that the number of data bits, $N_{b}=T_{h} / T$, transmitted per hop is a positive integer, which is strictly larger than 1 , i.e. we assume using slow frequency hopping.

\subsection{Channel Description}

The channel model considered in this paper is the commonly used finite-length tapped delay line model of a frequency-selective multipath channel [2], whose complex low-pass impulse response for subcarrier $u_{k}$ of user $k$ is given by:

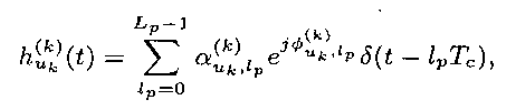

where $l_{p} T_{c}$ is the relative delay of the $l_{p}$-th path of user $k$ with respect to the main path, the phases $\left\{\phi_{u_{k}, l_{r}}^{(k)}\right\}$ are independent identically distributed (iid) random variables uniformly distributed in the interval $(0,2 \pi)$, whilst the $L_{p}$ tap weights $\left\{\alpha_{u_{k}, l_{p}}^{(k)}\right\}$ are independent Nakagami random variables with a pdf of [163]:

$$
\begin{gathered}
p\left(\alpha_{u_{k}, l_{p}}^{(k)}\right)=M\left(\alpha_{u_{k}, l_{p}}^{(k)}, m, \Omega_{u_{k}, l_{p}}^{(k)},\right. \\
M(R, m, \Omega)=\frac{2 m^{m} R^{2 m-1}}{\Gamma(m) \Omega^{m}} e^{(-m / \Omega) R^{2}},
\end{gathered}
$$

where $\Gamma(\cdot)$ represents the gamma function, and $m$ is the Nakagami$m$ fading parameter, which is defined as

$$
m=E^{2}\left[\left(\alpha_{u_{k}, l_{p}}^{(k)}\right)^{2}\right] / \operatorname{Var}\left[\left(\alpha_{u_{k}, l_{p}}^{(k)}\right)^{2}\right]
$$

. The parameter $m$ of the amplitude distribution characterizes the severity of the fading of the $l_{p}$-th resolvable path [164]. It is well known that $m=1$ corresponds to Rayleigh fading, $m=\infty$ corresponds to the non-fading condition, and $m=1 / 2$ corresponds to the so-called one-sided Gaussian fading, i.e the worst case fading condition. The Rician and lognormal distributions can also be closely approximated by the Nakagami distribution, when $m>1$. For more detailed information concerning the Nakagami distribution readers are referred to the excellent overview by Simon and Alouini [165]. The parameter $\Omega_{u_{k}, l_{p}}^{(k)}$ in Eq.(3) is the second moment of $\alpha_{u_{k}, l_{p}}^{(k)}$, i.e $\Omega_{u_{k}, l_{p}}^{(k)}=E\left[\left(\alpha_{u_{k}, l_{p}}^{(k)}\right)^{2}\right]$. We assume a negative exponentially decaying multipath intensity profile (MIP) given by:

$$
\Omega_{u_{k}, l_{p}}^{(k)}=\Omega_{u_{k}, 0}^{(k)} e^{-\eta l_{p}}, \quad \eta \geq 0,
$$

where $\Omega_{u_{k}, 0}^{(k)}$ is the average signal strength corresponding to the first resolvable path and $\eta$ is the rate of average power decay. Consequently, for an asynchronous CDMA system with $K$ users, the received signal takes the form:

$$
\begin{gathered}
r(t)=n(t)+\sqrt{2 P} \\
\sum_{k=1}^{K} \sum_{u_{k}=0}^{U_{k}-1} \sum_{l_{p}=0}^{L_{p}-1} \alpha_{u_{k}, l_{p}}^{(k)} d_{u_{k}}^{(k)}\left(t-l_{p} T_{c}-\tau_{k}\right) \\
c_{u_{k}}^{(k)}\left(t-l_{p} T_{c}-\tau_{k}\right) \cos \left(2 \pi f_{u_{k}}^{(k)} t+\psi_{u_{k}, l_{p}}^{(k)}\right),
\end{gathered}
$$

where $n(t)$ is the additive white Gaussian noise with zero mean and double-sided power spectral density of $N_{0} / 2$, while $\psi_{u_{k}, l_{p}}^{(k)}$ $=\left[\varphi_{u_{k}}^{(k)}+\phi_{u_{k}, l_{p}}^{(k)}-2 \pi f_{u_{k}}^{(k)}\left(\tau_{k}+l_{p} T_{c}\right)\right]$, which is assumed to be an iid random variable having a uniform distribution in $(0,2 \pi)$, and $\tau_{k}$ represents the propagation delay of user $k$.

\subsection{Receiver Model}

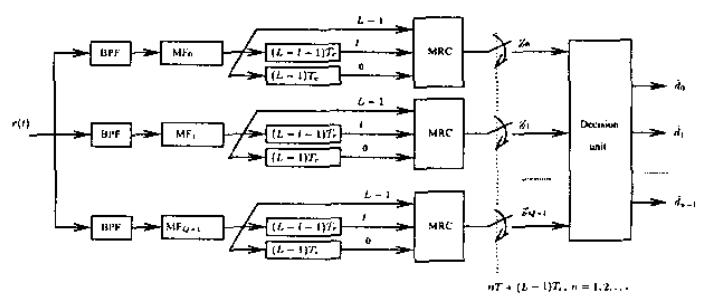

Figure 6: Receiver block diagram of the frequency-hopping multicarrier DS-CDMA systems.

Let the first user be the user-of-interest and consider the conventional matched filter based RAKE receiver with maximum ratio combining (MRC), as shown in Fig. 6, where the superscript and subscript of the reference user's signal has been omitted for notational convenience. In Fig. $6 L$ number of diversity branches are used by the receiver, where $1 \leq L \leq L_{p}$ is a variable, allowing us to study the effect of different diversity orders. Upon exploiting the knowledge of the $\mathrm{FH}$ patterns, detection can be implemented by demodulating only the $U_{k}$ active subcartiers, or alternatively, all $Q$ subcarriers can be always demodulated, while only $U_{k}$ MRC outputs are selected according to the FH patterns used for detection.

The $Q$ number of matched filters in Fig. 6 are matched to the reference user's CDMA codes used for spreading in the subbands associated with the $Q$ number of subcarriers, and are assumed to have achieved time synchronization. If we assume that perfect estimates of the channel tap weights and phases are available, then after appropriately delaying the individual matched filter outputs, in order to synchronize the $L$ number of path signals used by the RAKE combiner, the $q$ th MRC output sampled at $t=n T+(L-1) T_{c}$, in order to detect the $n$th symbol can be expressed as:

$$
Z_{q}=D_{q}[n]+I_{q},
$$

where $D_{q}[n]$ represents the desired direct component, while $I_{q}$ represents the interference plus noise component after the MRC. The final decision is based on the decision variable $Z_{q}$.

\subsection{System Performance and Discussion}

In this Section, the average bit error rate (BER) perfornance is evaluated as a function of the average signal-to-noise ratio (SNR) per bit, under the assumptions that the decision variable $Z_{q}$ in Eq.(6) is a Gaussian distributed variable, and the channel amplitudes $\left\{\alpha_{q, l}\right\}$ of the reference user are iid Nakagami- $m$ distributed variables.

To show the improvements due to diversity, Fig.7, Fig. 8 and Fig.9 depict the BER as a function of the average received SNR per bit. The individual curves in each figure are parameterized by the diversity order $L=1,2, \ldots, 6$. Fig.7 and Fig.8 represent the multipath Rayleigh fading environment $(m=1)$, while Fig. 9 characterises the Rician multipath fading environment $(m=5)$. We assumed that the $\mathrm{FH}$ patterns were designed from the constant-weight code $\mathrm{C}(32,16)$, there were $L_{p}=6$ resolvable paths, the number of active users was $K=50$, the bit-duration to chip-duration ratio was $N=127$. The MIP decay factor was $\eta=0$ for Fig. 7 and Fig. 9 , while $\eta=0.5$ for Fig.8, and finally, we had $m=1$ (Rayleigh fading) for Fig.7 and Fig.8, but $m=5$ (Rician fading) for Fig.9. From the results it is seen that the faster the MIP decays, the faster the incremental diversity improvement decreases. Nonetheless, the system BER performance is dramatically improved upon increasing the diversity order $L$ and the closer $L$ is to $L_{p}$, ie the more of the available multipath components are actually exploited by maximum ratio combining, the better.

Fig. 10 shows the BER performance of the proposed SFH /MC DS-CDMA system with respect to the multipath fading parameters 
$m=0.5,1,2,5,10,50$. As noted before, the Nakagami parameter $m$ represents the different fading environments, ranging from the worst-case one-sided Gaussian fading to Rayleigh, and finally to the most favourable non-fading case. We assumed that the $\mathrm{FH}$ patterns of each of the $K=50$ users in the system employed a constant-weight code $\mathrm{C}(32,16)$, there were $L_{p}=3$ number of resolvable multipaths at the receiver, and the diversity order of the receiver was $L=3$. Furthermore, we assumed that the number of chips per bit duration is $N=127$, and the MIP decay factor was $\eta=0$. As expected, for a given SNR per bit, the BER decreases upon increasing the value of $m$, which implies that the channel fading becomes less severe. The system performance is critically affected by the parameter $m$, ie the communication environment encountered.

In Fig. 11 SFH/MC DS-CDMA systems having a constant system bandwidth associated with $N Q=2^{12}$, but using various combinations of the number of subcarriers $Q$ and bit-duration to chipduration ratio of $N$ were considered. In this system, increasing the number of subcarriers means decreasing the 'hit' probability from the interfering users and simultaneously, decreasing the direct-sequ ence spread bandwidth of each subcarrier. The parameters used are shown in the figure. For a constant system bandwidth, and for $L_{p}=L=3$, we observe that, although $Q$ and $N$ changes ove a wide range, the $B E R$ performance remains indistinguishable for relatively low $\mathrm{SNR}$ per bit values, $(\leq 15 d B)$. However, for the higher SNR per bit values, $(>21 d B)$, the BER performance improves with increasing $N$

Since increasing the value of $N$ means increasing the DS spread bandwidth, and resulting in decreasing the chip-duration, consequently, for a given multipath fading environment with an average delay spread of $T_{m}$, the number of resolvable paths, $L_{p}=$ $T_{m} / T_{c}$, increases upon decreasing $T_{c}$. Hence, the assumption of $L_{p}=L=3$ in Fig. 11 is impractical. In Fig. 12 the performance of a SFH/MC DS-CDMA system over a given multipath fading environment having an average delay spread of $T_{\pi_{n}}$ was considered. Here we assumed that there was one resolvable path at the receiver for the system with $N=16$. Consequently, the number of resolvable paths was $L_{p}=2,4,8,16$ for the systems with $N=32,64,128,256$. Furthermore, we assumed that the receiver could combine all the resolvable paths. Other parameters related to the computations were the same, as in Fig. 11, which are shown in the figure. The results demonstrate that the BER performance is significantly improved, when increasing $N$. Hence, for signals undergoing severe fading, a number of independent channels are necessary for their transmission, in order to enhance the performance.

For the systems considered in Fig. 12 to achieve the best BER performance the receiver has to have a high diversity order. For example, for the system with $N=256$ to achieve the best BER performance, the receiver has to combine all the 16 multipath signals. However, presently the implementation of such a complex receiver is impractical. Hence, in Fig. 13 we considered a receiver with a maximum diversity order of $L=3$, although a higher number of resolvable paths, $L_{p}$, was available at the receiver. From the results we infer that the curve associated with $Q=64, N=64$, or $L_{\mathrm{p}}=4, L=3$ achieves the best BER performance.

From the results of Fig. 11 to Fig.13, we conclude that for a SFH/MC DS-CDMA system with a constant system bandwidth, provided the receiver is capable of combining a constant number of multipaths, namely $L$, then according to the average delay spread of the channel, the DS spread bandwidth of each sub-band can be adjusted, so that the resulting number of resolvable paths, $L_{p}$, is as close to $L$ as possible. Then the receiver can efficiently utilize the energy dispersed over the multipath components. The number of sub-bands, consequently, can be obtained by dividing the system bandwidth by the required DS spread bandwidth.

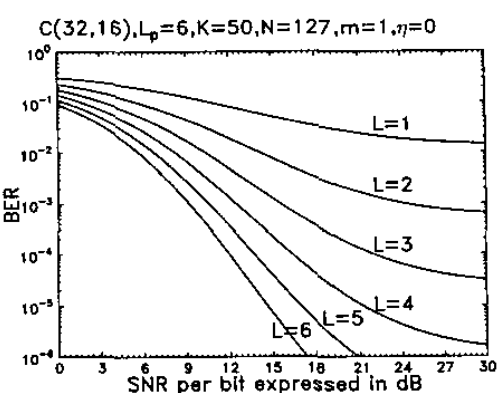

Figure 7: BER versus SNR per bit performance for constantweight code based SFH/MC DS-CDMA systems over multipath Rayleigh fading channels $(m=1)$ upon varying diversity order $L$, under constant-weight code $\mathrm{C}(32,16)$, resolvable paths $L_{p}=6$, number of users $K=50$, bit-duration to chip-duration ratio $N=127$ and MIP decay factor $\eta=0$.

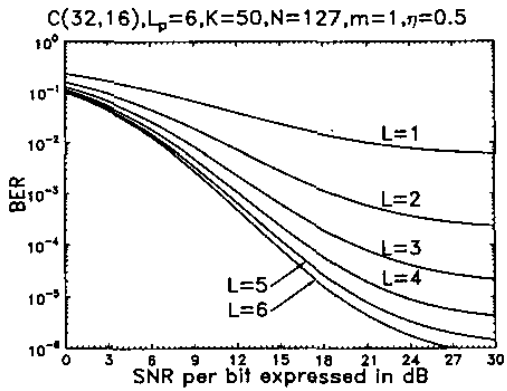

Figure 8: BER versus SNR per bit performance for constantweight code based SFH/MC DS-CDMA systems over multipath Rayleigh fading channels upon varying diversity order $L$ for $\eta=$ 0.5

\section{AOFDM VERSUS ADAPTIVE MC-CDMA}

\subsection{System Model and AOFDM Switching Levels}

Orthogonal Frequency Division Multiplex (OFDM) based multicarrier systems $[3,4]$ approach the theoretically highest possible $2 \mathrm{Bd} / \mathrm{Hz}$ bandwidth efficiency quantified by Shannon, since they typically require only a small raised-cosine excess bandwidth for Nyquist-filtering. Hence, they are considered attractive for downlink wireless Internet services in future fourth generation (4G) systems as well as in high-speed Wireless Local Area Networks known as WLANs. However, OFDM in its basic form cannot fully benefit from the multi-path diversity potential of wideband channels.

Multi-Carrier Code Division Multiple Access (MC-CDMA) [60] constitutes an OFDM-based frequency domain spreading technique, which exploits frequency domain diversity and constitutes an attractive multiple access scheme for employment in synchronous environments. It was reported that the synchronisation requirement of MC-CDMA is within $10 \%$ of the frame length [166]. Thus, an MC-CDMA system having the appropriate modem parameters can be used as a multiple access scheme in the down link of fixed or slowly moving terminals, where near-synchronous operation is feasible. Since MC-CDMA facilitates diversity reception similarly to a Rake receiver, the performance of single-user MC-CDMA is characterised by that of an ideal Rake receiver. In a multi-user scenario joint-detection assisted MC-CDMA employing the MMSEBDFE [167] receiver approaches the single-user performance.

When channel coding is employed in conjunction with fre- 


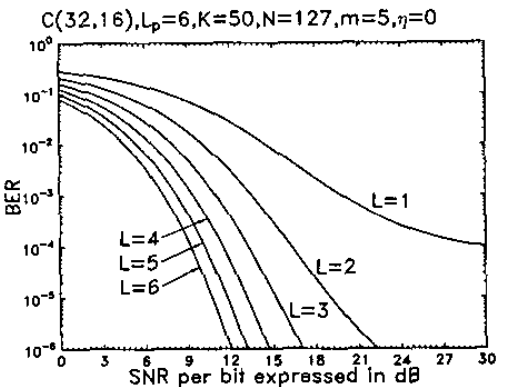

Figure 9: BER versus SNR per bit performance for constantweight code based SFH/MC DS-CDMA systems over multipath Rician fading channels upon varying diversity order $L$ for $m=5$.

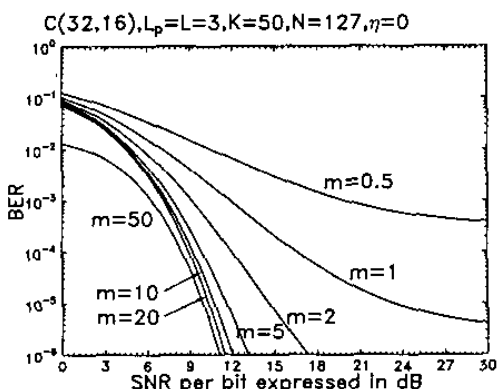

Figure 10: BER versus SNR per bit performance for constantweight code based SFH/MC DS-CDMA systems over different fading channels upon varying the fading parameter $m$.

quency domain interleaving, OFDM substantially benefits from the frequency domain diversity. However, OFDM may not be capable of exploiting the diversity potential of the channel to the same extent as MC-CDMA. Hence, it is interesting to compare the coded BERs of OFDM and MMSE-BDFE aided MC-CDMA in conjunction with concatenated turbo codes and space-time block codes over wideband Rayleigh channels.

Various combinations of Space-Time (ST) codes and channel codes can be used for transmission over wideband fading channels $[6,168]$. An attractive option is to use a half-rate turbo convolutional code concatenated to a space-time block code using two transmit antennas and to expand the signal constellation to a higher order modulation mode in order to match the throughput of the system using no channel coding. Another approach to maintaining a high effective throughput is to use a high-rate turbo $\mathrm{BCH}$ code in conjunction with a ST trellis code or ST block code and a lower order modulation mode, than in case of the half-rate FEC scheme. It was reported in $[6,168]$ that the former approach gives a lower BER, than the latter. Hence, we will employ a half-rate turbo convolutional code in our comparative study.

Adaptive modulation $[169,170]$ attempts to provide the highest possible throughput given the current channel quality, while maintaining the required data transmission integrity. We used constant-power Adaptive Quadrature Amplitude Modulation (AQAM) $[4,5]$. Again, wideband fading exhibits two-dimensional channel quality variation, namely both time domain variation and frequency domain variation, and OFDM lends itself to exploiting these twodimensional channel quality variations $[171,172,3]$. In other words, time domain adaptivity and frequency domain adaptivity can be simultaneously exploited in OFDM. By contrast, while providing frequency domain diversity with the aid of averaging the channel

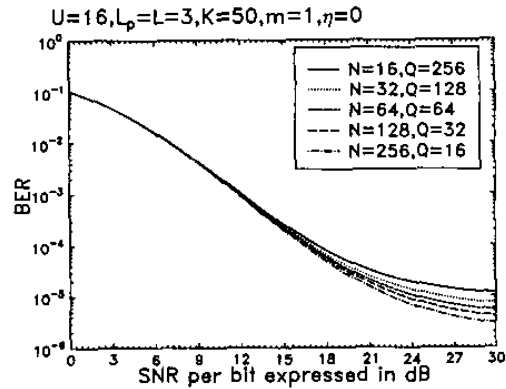

Figure 11: BER versus SNR per bit performance for constantweight code based SFH/MC DS-CDMA systems upon varying the value of $N$ and $Q$ under $L_{p}=L=3$.

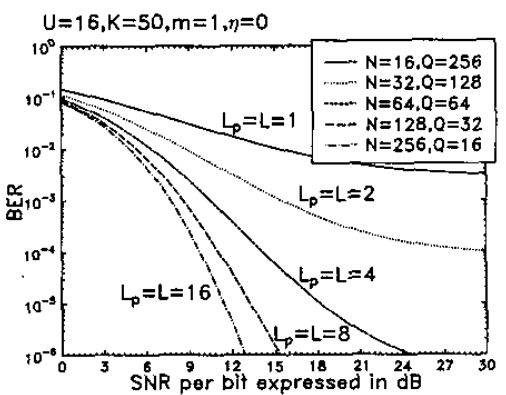

Figure 12: BER versus SNR per bit performance for constantweight code based SFH/MC DS-CDMA systems upon varying the value of $N$ and $Q$ under $L_{p}=L=1,2,4,8,16$.

qualities of several sub-carriers, MC-CDMA is less amenable to frequency domain adaptation, than to time domain adaptation.

The aim of this contribution is to compare the performances of the combined adaptive OFDM and MC-CDMA modems. Although adaptive coded multi-carrier modulation systems have been extensively studied $[171,173,174]$, the effect of diversity has not been considered.

Figure 14 portrays the stylised transmitter structure of our system. The source bits are channel coded by a half-rate turbo convolutional encoder $[175,6]$ using a constraint length of $K=3$ as well as an interleaver size of $L=3072$ bits and interleaved by a random block interleaver. Then, the AQAM block selects a modulation mode from the set of no transmission, BPSK, QPSK, 16-QAM and 64-QAM depending on the instantaneous channel quality perceived by the receiver, according to the predetermined SNR-dependent switching thresholds. It is assumed that the perfectly estimated channel quality experienced by receiver $A$ is fed back to transmitter $B$ superimposed on the next burst transmitted to receiver $B$. The modulation mode switching levels of our AQAM scheme determine the average BER as well as the average throughput. A set of optimum switching thresholds was derived in [176] for transmission over flat Rayleigh fading channels. However, AQAM modems employing these switching thresholds inevitably exhibit a variable average BER across the SNR range, despite aiming for a given target BER, namely $B_{t}$. In order to achieve a constant target $\mathrm{BER}$, while maintaining the maximum possible throughput, a new set of SNR-dependent switching thresholds was devised for the transmission over wideband channels [177, 178]. Figure 15 illustrates the switching levels optimised for both adaptive OFDM and adaptive MC-CDMA for the target BER of $B_{t}=$ $10^{-3}$. The optimum switching levels decrease, as the average chan- 


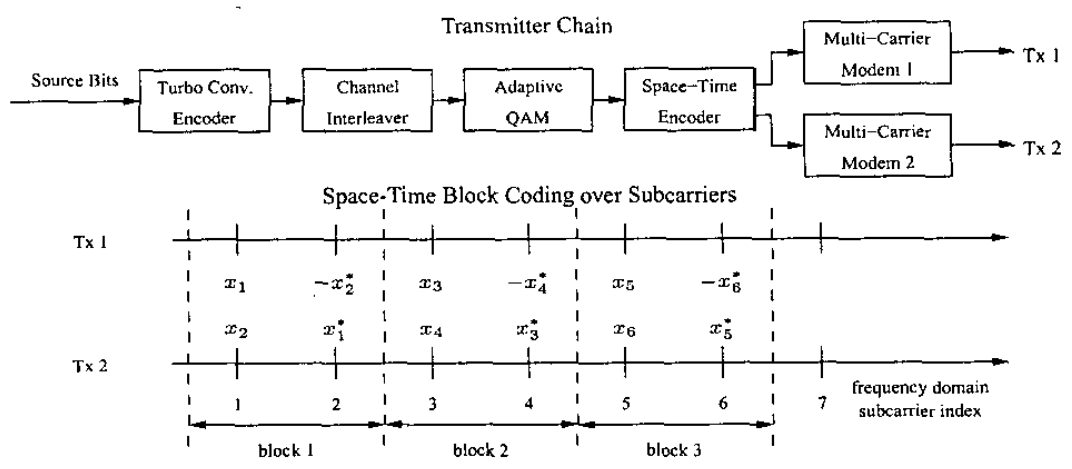

Figure 14: Transmitter structure and space-time block encoding scheme

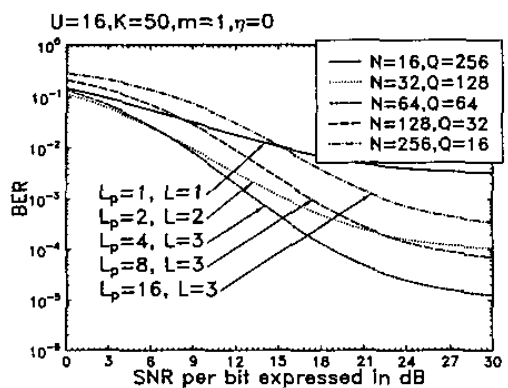

Figure 13: BER versus SNR per bit performance for constantweight code based SFH/MC DS-CDMA systems upon varying the value of $N$ and $Q$ under a maximum diversity order of $L=3$ and $L_{p}=1,2,3,4,8,16$.

nel SNR increases and hence higher-throughput modulation modes can be invoked more frequently. Figure 15 also shows the 'avalanche' SNR, beyond which adaptive mode switching is abandoned in favour of the fixed highest-order modulation mode, namely 64-QAM, since the BER of 64-QAM satisfies the target BER requirement

The modulated symbol is now space-time encoded. As seen at the bottom of Figure 14, Alamouti's space-time block code $[179,6]$ is applied across the frequency domain. A pair of the adjacent sub-carriers belonging to the same space-time encoding block is assumed to have the same channel quality. We employed a Wireless Asynchronous Transfer Mode (W-ATM) channel model [4 pp.474] transmitting at a carrier frequency of $60 \mathrm{GHz}$, at a sampling rate of $225 \mathrm{MHz}$ and employing 512 sub-carriers. Specifcally, we used a 3-path fading channel model, where the average SNR of each path is given by $\bar{\gamma}_{1}=0.79192 \bar{\gamma}, \bar{\gamma}_{2}=0.12424 \bar{\gamma}$ and $\bar{\gamma}_{3}=0.08384 \bar{\gamma}$. Each channel associated with a different antenna is assumed to exhibit independent fading.

\subsection{Uncoded Adaptive System}

The simulation results for our uncoded adaptive modems are presented in Figure 16. Since we employed the optimum switching levels, both our adaptive OFDM (AOFDM) and the adaptive single-user MC-CDMA (AMC-CDMA) modems maintain the constant target BER of $10^{-3}$ up to the 'avalanche' SNR value, and then follow the BER curve of the 64-QAM mode. However, 'full-user' AMC-CDMA supporting $U=16$ users with the aid of a spreading factor of $G=16$ and employing the MMSE-BDFE Joint Detection (JD) receiver [167] exhibits a slightly higher average BER, than the target of $B_{t}=10^{-3}$ due to the residual Multi-User Interference (MUI) of the imperfect joint detector. Since we derived the optimum switching levels based on a single-user system, the

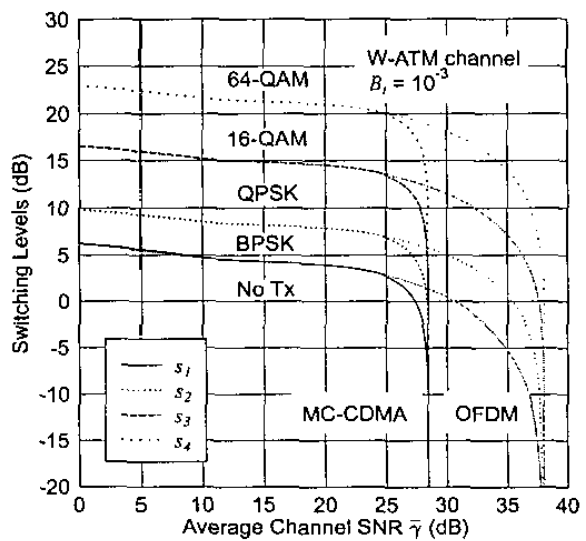

Figure 15: The optimum switching levels devised for the target BER of $B_{t}=10^{-3}$, when using $1 \mathrm{Tx}$ antenna and $1 \mathrm{Rx}$ antenna. The W-ATM channel model [4, pp.474] is assumed for MCCDMA. The switching levels for OFDM were obtained for narrowband Rayleigh channels, which can be used for any multi-path profile, since OFDM renders the dispersive channel non-dispersive. (c) Hanzo ${ }^{1}$, Münster, Choi and Keller [3]

levels are no longer optimum, when residual MUI is present. The average throughputs expressed in terms of Bits Per Symbol (BPS) steadily increase and reach the throughput of 64-QAM, namely 6 BPS. The throughput degradation of 'full' user MC-CDMA was within a fraction of one dB. Observe in Figure 16(a) that the analytical and simulation results are in good agreement, which we denoted by the lines and distinct symbols, respectively.

The effects of ST coding on the average BPS throughput are displayed in Figure 16(b). Specifically, the thick lines represent the average BPS throughput of our AMC-CDMA scheme, while the thin lines represent those of our AOFDM modem. The four pairs of hollow and filled markers associated with four ST-coded scenarios represent the BPS throughput versus SNR values associated with fixed-mode OFDM and fixed-mode MMSE-BDFE JD assisted MC-CDMA. Specifically, the right most markers correspond to the $1-\mathrm{Tx} / 1-\mathrm{Rx}$, the second to the $2-\mathrm{Tx} / 1-\mathrm{Rx}$, the third to the 1-Tx / 2-Rx and the left most to the 2-Tx / 2-Rx scenarios. First of all, we can observe that the BPS throughput curves of OFDM and single-user MC-CDMA are close to each other, namely within $1 \mathrm{~dB}$ for most of the SNR range. This is surprising, considering that the fixed-mode MMSE-BDFE JD assisted MC-CDMA scheme was reported to exhibit around $10 \mathrm{~dB}$ SNR gain at a BER of $10^{-3}$ and $30 \mathrm{~dB}$ gain at a BER of $10^{-6}$ over OFDM $[3,65]$. This is confirmed in Figure $16(\mathrm{~b})$ by observing that the SNR difference between the $o$ and - markers is around $10 \mathrm{~dB}$, regardless whether the 4,2 or 1 BPS scenario is concemed.

Let us now compare the SNR gains of the adaptive modems 


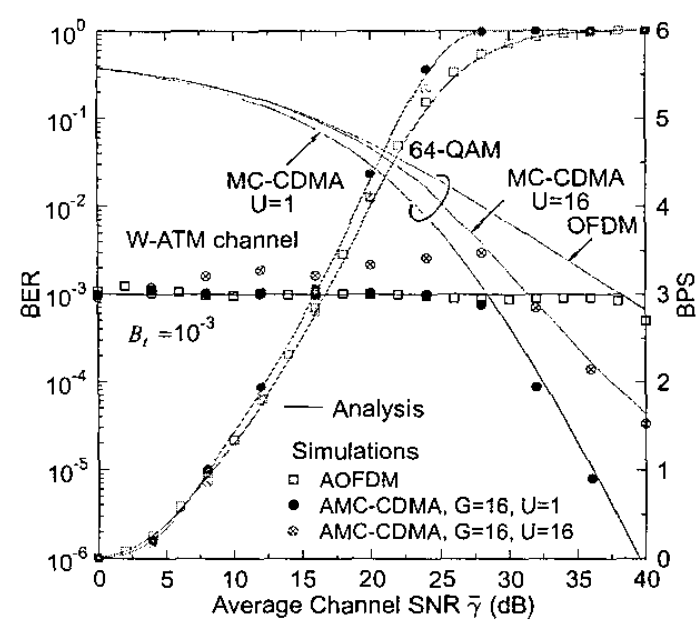

(a) BER and Throughput, No ST coding

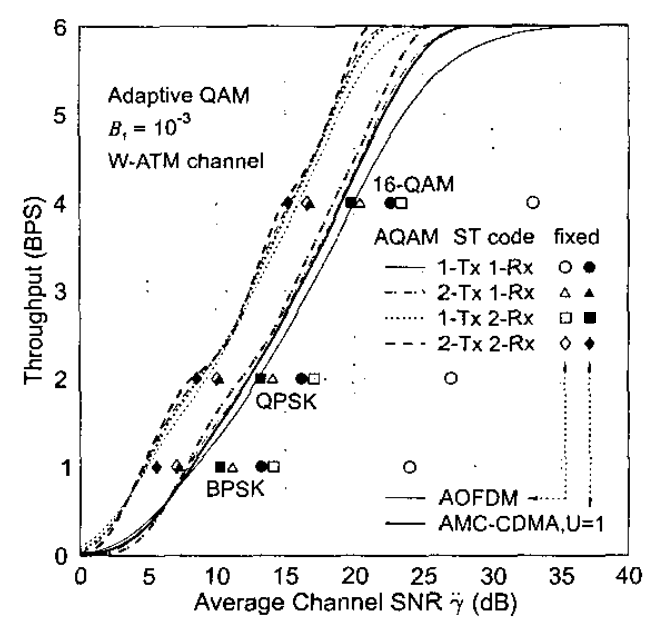

(b) Throughput with ST coding

Figure 16: Performance of uncoded five-mode AOFDM and AMC-CDMA. The target BER is $B_{t}=10^{-3}$ transmitting over the W-ATM channel [4, pp.474]. (a) The constant average BER is maintained for AOFDM and single user AMC-CDMA, while 'full-user' AMC-CDMA exhibits a slightly higher average BER due to the residual MUI. (b) The SNR gain of adaptive modems decreases as ST coding increases the diversity order. The BPS curves appear in pairs, corresponding to AOFDM and AMC-CDMA - indicated by the thin and thick lines, respectively - for each of the four different ST code configurations. The markers represent the SNRs required by the fixed-mode OFDM and MC-CDMA schemes for maintaining the target BER of $10^{-3}$ in conjunction with the four ST-coded schemes (C)Hanzo ${ }^{1}$, Münster, Choi and Keller [3].

over the fixed modems. The SNR difference between the BPS curve of AOFDM and the fixed-mode OFDM represented by the symbol $o$ at the same throughput is around $15 \mathrm{~dB}$. The corresponding SNR difference between the adaptive and fixed-mode 4,2 or 1 BPS MC-CDMA modem is around 5dB. More explicitly, since in the context of the W-ATM channel model [4, pp.474] fixed-mode MC-CDMA appears to exhibit a $10 \mathrm{~dB}$ SNR gain over fixed-mode OFDM, the additional 5dB SNR gain of AMC-CDMA over its fixed-mode counterpart results in a total SNR gain of $15 \mathrm{~dB}$ over fixed-mode OFDM. Hence ultimately the performance of AOFDM and AMC-CDMA becomes similar.

Let us now examine the effect of ST block coding. The SNR gain of the fixed-mode scheme due to the introduction of a 2-Tx/ I-Rx ST block code is represented as the SNR difference between the two right most markers. These gains are nearly $10 \mathrm{~dB}$ for fixedmode OFDM, while they are only $3 \mathrm{~dB}$ for fixed-mode MC-CDMA modems. However, the corresponding gains are less than $1 \mathrm{~dB}$ for both adaptive modems. Since the transmitter power is halved due to using two Tx antennas in the ST codec, a $3 \mathrm{~dB}$ channel SNR penalty was already applied to the curves in Figure 16(b). The introduction of the second receive antenna instead of the second transmit antenna eliminates this $3 \mathrm{~dB}$ penalty. Finally, the $2-\mathrm{Tx} / 2-\mathrm{Rx}$ system gives around 3-4dB SNR gain in the context of fixed-mode OFDM and a 2-3dB SNR gain for MC-CDMA, in both cases over the 1$\mathrm{Tx} / 2-\mathrm{Rx}$ system. By contrast, the gain of the $2-\mathrm{Tx} / 2-\mathrm{Rx}$ scheme over the 1-Tx / $2-R x$ based adaptive modems was, again, less than $\mathrm{ldB}$ in Figure 16(b). More importantly, for the 2-Tx / 2-Rx scenario the advantage of employing adaptive modulation vanishes, since the fixed-mode MC-CDMA modem performs as well as the AMC-CDMA modem in this scenario. Moreover, the fixed-mode MC-CDMA modem still outperforms the fixed-mode OFDM modem by about $2 \mathrm{~dB}$. We conclude that since the diversity-order increases with the introduction of ST block codes, the channel quality variation becomes sufficiently low for the performance advantage of adaptive modems to vanish. This is achieved at the price of a higher complexity due to employing two transmitters and two receivers.

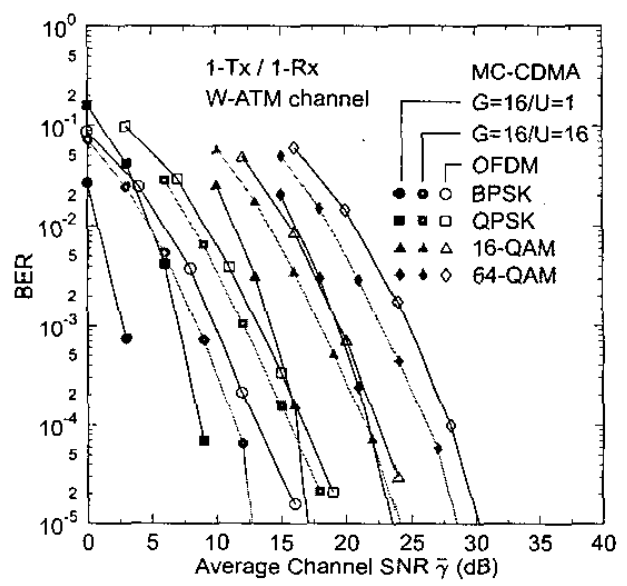

Figure 17: Performance of turbo convolutional coded fixed-mode OFDM and MC-CDMA over the W-ATM channel of $[4$, pp.474] JD MC-CDMA still outperforms OFDM. However, the SNR gain of JD MC-CDMA over OFDM is reduced to $1-2 \mathrm{~dB}$ at a BER of $10^{-4}$ (C) Hanzo ${ }^{1}$, Münster, Choi and Keller [3].

\subsection{Turbo-Coded Fixed Modem}

When channel coding is employed in the fixed-mode multi-carrier systems, it is expected that OFDM benefits more substantially from the frequency domain diversity than MC-CDMA, which benefited more than OFDM without channel coding. The simulation results depicted in Figure 17 show that the various turbo-coded fixedmode MC-CDMA systems consistently outperform OFDM. However, the SNR differences between the turbo-coded BER curves of OFDM and MC-CDMA are reduced considerably.

\subsection{Turbo Coded Adaptive System}

The performance of the concatenated ST block coded and turbo convolutional coded adaptive modems is depicted in Figure 18 
We applied the optimum set of switching levels designed fot the uncoded BER of $3 \times 10^{-2}$. This uncoded target BER was obtained from the relations of the uncoded and the turbo coded BPSK modems employing the same coding parameters over AWGN channels, with the ultimate objective of obtaining a coded BER below $10^{-7}$ for our adaptive modems. However, our simulation results yielded zero bit errors when transmitting $10^{9}$ bits, except for some SNRs, when employing only a single antenna.

Figure 18(a) shows the BER of our turbo coded adaptive modems, when a single antenna is used. We observe in the figure that the BER reaches its highest value around the 'avalanche' SNR point, where the adaptive modulation scheme consistently activates 64 QAM. The system is most vulnerable around this point. In order to interpret this phenomenon, let us briefly consider the associated interleaving aspects. For practical reasons we have used a fixed interleaver length of $L=3072$ bits. When the instantaneous channel quality was high, the $L=3072$ bits were spanning a shorter timeduration during their passage over the fading channel. Hence the channel errors appeared more bursty, than in the lower-throughput AQAM modes, which transmitted the $L=3072$ bits over a longer duration, hence dispersing the error bursts over a longer duration of time. The associated more random dispersion of erroneous bits enhances the coding power of the turbo code. On the other hand, in the SNR region beyond the 'avalanche' SNR point the system exhibited a lower uncoded BER, reducing the coded BER even further. This observation suggests that further research ought to determine the set of switching thresholds for a coded adaptive system.

We can also observe that the turbo coded BER of AOFDM is higher than that of AMC-CDMA in the SNR rage of 10-20dB, even though the uncoded BER is the same. This appears to be the effect of the limited exploitation of frequency domain diversity in coded OFDM, compared to MC-CDMA, which leads to a more bursty uncoded error distribution, hence degrading the turbo coded performance. The fact that ST block coding aided multiple antenna systems show virtually error free performance corroborates our argument.

Figure 18(b) compares the throughputs of the coded adaptive modems and the uncoded adaptive modems exhibiting a comparable average BER. The SNR gains due to channel coding were in the range of $0 \mathrm{~dB}$ to $8 \mathrm{~dB}$ depending on the SNR region and the employed scenarios. Each bundle of throughput curves corresponds to the scenarios of $1-T x / 1-R x$ OFDM, $1-T x / 1-R x$ MCCDMA, 2-Tx/1-Rx OFDM, 2-Tx/1-Rx MC-CDMA, 1-Tx/2-Rx OFDM, 1-Tx/2-Rx MC-CDMA, 2-Tx/2-Rx OFDM and 2-Tx/2$\mathrm{Rx}$ MC-CDMA starting from the far right curve for the throughput values higher than 0.5 BPS. The SNR difference between the throughput curves of the ST and turbo coded AOFDM and those of the corresponding AMC-CDMA schemes was reduced compared to the uncoded performance curves of Figure 16(b). The SNR gain owing to ST block coding in the context of AOFDM and AMCCDMA was limited to about $1 \mathrm{~dB}$ due to the halved transmitter power. Therefore, again, ST block coding appears to be less effective for adaptive modems.

\section{CONCLUSION}

Following a historical perspective on multi-carrier communications, the achievable performance of slow frequency-hopped MC-CDMA was characterised, followed by a quantitative discussion on the performance of AOFDM and frequency-domain spreading aided adaptive MC-CDMA assisted by turbo coding and space-time block coding.

More explicitly, the performance of ST block coded constantpower adaptive multi-carrier modems employing optimum SNRdependent modem mode switching levels was investigated. The adaptive modems maintained the constant target BER, whilst maximising the average throughput. As expected, it was found that ST block coding reduces the relative performance advantage of adaptive modulation, since it increases the diversity order and eventually reduces the channel quality variations. When turbo convolutional coding was concatenated to the ST block codes, near-error- tree transmission was achieved at the expense of the halving the average throughput. Compared to the uncoded system, the turbo coded system was capable of achieving higher throughput in the low SNR region at the cost of higher complexity. The study of the relationship between the uncoded BER and the corresponding coded BER showed that adaptive modems obtain higher coding gains, than that of fixed modems. This was due to the fact that the adaptive modem avoids burst errors even in deep channel fades by reducing the number of bits per modulated symbol eventually to zero.

\section{REFERENCES}

[1] J. Blogh and L. Hanzo, $3 G$ Systems and Intelligent Networking. John Wiley and IEEE Press, 2002. (For detailed contents, please refer to http://www-mobile.ecs.soton.ac.uk.).

[2] L. Hanzo, L. L. Yang, E. L. Kuan, and K. Yen, Single- and MultiCarrier CDMA. John Wiley and IEEE press, 2003.

[3] L. Hanzo and M. Münster and B-J. Choi and T. Keller, OFDM versus MC-CDMA for broadband multi-user communications, WLANS and broadcasting. John Wiley and IEEE press, 2003.

[4] L, Hanzo, W. Webb, and T. Keller, Single- and Multi-Carrier Quadrature Amplitude Modulation: Principles and Applications for Personal Communications, WLANs and Broadcasting. John Wiley and IEEE Press, 2000.

[5] L. Hanzo, C. Wong, and M. Yee, Adaptive Wireless Transceivers. John Wiley, IEEE Press, 2002. (For detailed contents, please refer to h:tp://www-mobile.ecs.soton.ac.uk.).

[6] L. Hanzo, T. Liew, and B. Yeap, Turbo Coding, Turbo Equalisation and Space-Time Coding. John Wiley, IEEE Press, 2002. (For detailed contents, please refer to http://www-mobile.ecs.soton.ac.uk.).

[7] Z. Wang and G.B. Giannakis, "Wireless Multicarrier Communications," Signal Processing Magazine, pp. 29-48, May 2000.

[8] R. W. Chang, "Synthesis of band-limited orthogonal signals for multichannel data transmission," Bell Systems Technical Journal, vol. 46, pp. 1775-1796, December 1966.

[9] M. Zimmermann and A. Kirsch, "The AN/GSC10/KATHRYN/variable rate data modem for HF radio," IEEE Transactions on Communication Technology, vol. CCM-15, pp. 197-205, April 1967.

[10] E. Powers and M. Zimmermann, "A digital implementation of a multichannel data modem," in Proceedings of the IEEE International Conference on Communications, (Philadelphia, USA), 1968.

[11] B. R. Saltzberg, "Performance of an efficient parallel data transmission system," IEEE Transactions on Communication Technology, pp. 805-813, December 1967.

[12] R. Chang and R. Gibby, "A theoretical study of performance of an orthogonal multiplexing data transmission scheme," JEEE Transactions on Communication Technology, vol. COM-16, pp. 529-540, August 1968.

[13] S. B. Weinstein and P. M. Ebert, "Data transmission by frequency division multiplexing using the discrete fourier transform," IEEE Transactions on Communication Technology, vol. COM-19, pp. 628-634, October 1971 .

[14] A. Peled and A. Ruiz, "Frequency domain data transmission using reduced computational complexity algorithms," in Proceedings of International Conference on Acoustics, Speech, and Signal Processing, ICASSP'80, vol. 3, (Denver, CO, USA), pp. 964-967, IEEE, 9-11 April 1980.

[15] B. Hirosaki, "An orthogonally multiplexed QAM system using the discrete fourier transform," IEEE Transactions on Communications, vol. COM-29, pp. 983-989, July 1981 .

[16] H. Kolb, "Untersuchungen über ein digitales mehrfrequenzverfahren zur datenübertragung," in Ausgewählte Arbeiten über Nachrichtensysteme, no. 50, Universität Erlangen-Nürnberg, 1982.

[17] H. Schüssler, "Ein digitales Mehrfrequenzverfahren zur Datenübertragung," in Professoren-Konferenz, Stand und Entwicklungsaus. sichten der Daten und Telekommunikation, (Darmstad,, Germany), pp. 179-196, 1983.

[18] L. Cimini, "Analysis and simulation of a digital mobile channel using orthogonal frequency division multiplexing," IEEE Transactions on Communications, vol. 33, pp. 665-675, July 1985.

[19] K. Preuss, "Ein Parallelverfahren zur schnellen Datenübertragung Im Ortsnetz," in Ausgewählte Arbeiten über Nachrichtensysteme. no. 56, Universität Erlangen-Nümberg, 1984. 


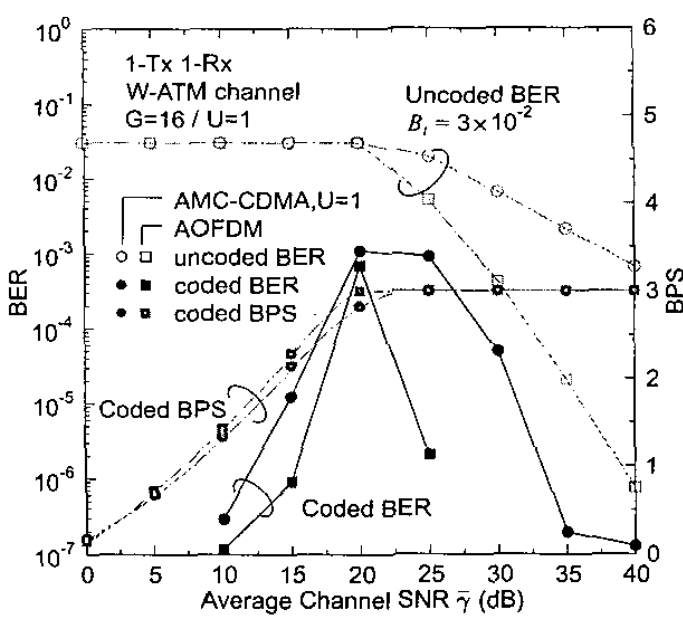

(a) BER

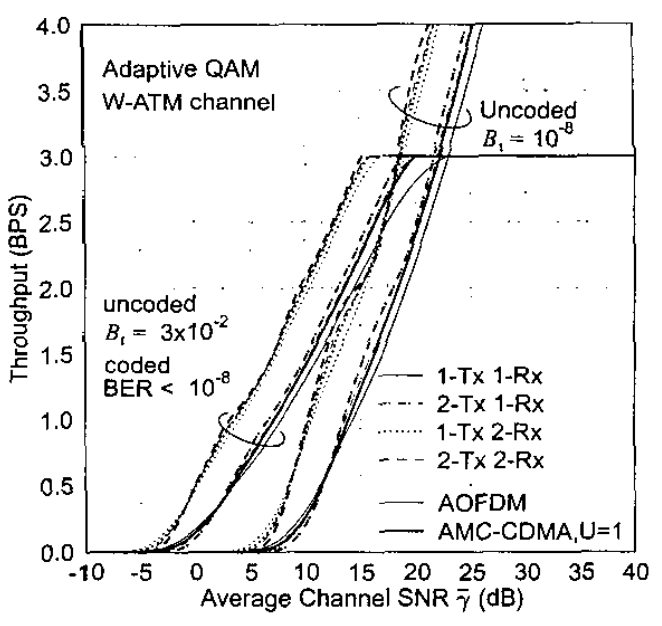

(b) Throughput

Figure 18: Performance of the concatenated ST block coded and turbo convolutional coded adaptive OFDM and MC-CDMA systems over W-ATM channel of $[4, \mathrm{pp} .474]$. The uncoded target BER is $3 \times 10^{-2}$. The coded BER was less than $10^{-8}$ for most of the SNR range, resulting in virtually error free transmission. (a) The coded BER becomes higher near the 'avalanche' SNR point, when a single antenna was used. (b) The coded adaptive modems have SNR gains up to $7 \mathrm{~dB}$ compared to their uncoded counterparts achieving a comparable average BER @CHanzo ${ }^{1}$, Münster, Choi and Keller [3].

[20] R. Rückriem, "Reatisierung und messtechnische Untersuchung an einem digitalen Parallelverfahren zur Datenübertragung im Fernsprechkanal," in Ausgewählte Arbeiten über Nachrichtensysteme, no. 59, Universität Erlangen-Nürnberg, 1985.

[21] F. Mueller-Roemer, "Directions in audio broadcasting," Journal Audio Engineering Society, vol. 41, pp. 158-173, March 1993.

[22] G. Plenge, "DAB - a new radio broadcasting system - state of development and ways for its introduction," Rundfunktech. Mitt. vol. 35, no. 2,1991 .

[23] M. Alard and R. Lassaile, "Principles of modulation and channel coding for digital broadcasting for mobile receivers," $E B U$ Review, Technical No. 224, pp. 47-69, August 1987.

[24] Proceedings of Ist International Symposium.DAB, (Montreux, Switzerland), June 1992

[25] 1. Kalet, "The multitone channei," IEEE Transactions on Communications, vol. 37, pp. 119-124, February 1989.

[26] W. Webb and R. Steele, "Variable rate QAM for mobile radio" IEEE Transactions on Communications, vol. 43, pp. 2223-2230, July 1995 .

[27] L. Hanzo, "Bandwidth-efficient wireless multimedia communications," Proceedings of the IEEE, vol. 86, pp. 1342-1382, July 1998.

[28] S. Nanda, K. Balachandran, and S. Kumar, "Adaptation techniques in wireless packet data services," IEEE Commtnications Magazine, vol. 38, pp. 54-64, January 2000

[29] L. Hanzo, F. Somerville, and J. Woodard, Voice Compression and Communications: Principles and Applications for Fixed and Wireless Channels. IEEE Press and John Wiley, 2001. (For detailed contents and sample chapters please refer to http://wwwmobile.ecs.soton.ac.uk.).

[30] L. Hanzo, P. Cherriman, and J. Streit, Wireless Video Communications: From Second to Third Generation Systems, WLANs and Be yond. IEEE Press and John Wiley, 2001. (For detailed contents please refer to http://www-mobile.ecs.soton.ac.uk.)

[31] B. Hirosaki, "An analysis of automatic equalizers for orthogonally multiplexed QAM systems," IEEE Transactions on Communications, vol. COM-28, pp. 73-83, January 1980.

[32] P. Bello, "Selective fading limitations of the KATHRYN modem and some system design considerations," IEEE Trabsactions on Communications Technology, vol. COM-13, pp. 320-333, September 1965.

[33] K. Fazel and G. Fettweis, eds., Multi-Carrier Spread-Spectrum. Dordrecht: Kluwer, 1997. ISBN 0-7923-9973-0.

[34] F. Classen and H. Meyr, "Synchronisation algorithms for an OFDM system for mobile communications," in Codierung für Quelle. Kanal und Übertragung, no. 130 in ITG Fachbericht, (Berlin), pp. $105-$ 113, VDE-Verlag, 1994.
[35] F. Classen and H. Meyr, "Frequency synchronisation algorithms for OFDM systems suitable for communication over frequency selective fading channels," in Proceedings of IEEE VTC '94, (Stockholm, Sweden), pp. 1655-1659, IEEE, 8-10 June 1994.

[36] R. van Nee and R. Prasad, OFDM for wireless multimedia communications. London: Artech House Publishers, 2000.

[37] P. Vandenameele, L. van der Perre, and M. Engels, Space division multiple access for wireless local area networks. Kluwer, 2001.

[38] S. Shepherd, P. van Eetvelt, C. Wyatt-Millington, and S. Barton, "Simple coding scheme to reduce peak factor in QPSK multicarrie modulation," Electronics Letters, vol. 31, pp. 1131-1132, July 1995.

[39] A. E. Jones, T. A. Wilkinson, and S. K. Barton, "Block coding scheme for reduction of peak to mean envelope power ratio of multicarrier transmission schemes," Electronics Letters, vol, 30 , pp. 2098-2099, December 1994.

[40] D. Wulich, "Reduction of peak to mean ratio of multicarrier modulation by cyclic coding," Electronics Letters, vol. 32, pp. 432-433, 1996

[41] S. Müller and J. Huber, "Vergleich von OFDM-Verfahren mit reduzierter Spitzenleistung," in 2. OFDM-Fachgespräch in Braunschweig, 1997.

[42] M. Pauli and H.-P. Kuchenbecker, "Neue Aspekte zur Reduzierung der durch Nichtlinearitäten hervorgerufenen Außerbandstrahlung eines OFDM-Signals," in 2. OFDM-Fachgespräch in Braunschweig, 1997.

[43] T. May and H. Rohling, "Redıktion von Nachbarkanalstörungen in OFDM-Funkübertragungssystemen," in 2. OFDM-Fachgespräch in Braunschweig, 1997.

[44] D. Wulich, "Peak factor in orthogonal multicarrier modulation with variable levels," Electronics Letters, vol. 32, no. 20, pp. 1859-1861, 1996.

[45] H. Schmidt and K. Kammeyer, "Adaptive Subträgerselektion zur Reduktion des Crest faktors bei OFDM," in 3. OFDM Fachgespräch in Braunschweig, 1998.

[46] R. Dinis and A. Gusmao, "Performance evaluation of OFDM trans" mission with conventional and 2-branch combining power amplification schemes," in Proceeding of IEEE Global Telecommunications Conference, Globecom 96, (London, UK), pp. 734-739, IEEE, 1822 November 1996.

[47] R. Dinis, P. Montezuma, and A. Gusmao, "Performance trade-offs with quasi-linearly amplified $O F D M$ through a 2-branch combining technique," in Proceedings of IEEE VTC'96, (Atlanta, GA, USA), pp. 899-903, IEEE, 28 April-1 May 1996. 
[48] R. Dinis, A. Gusmao, and J. Fernandes, "Adaptive transmission techriques for the mobile broadband system," in Proceeding of ACTS Mobile Communication Summit '97. (Aalborg, Denmark), pp. 757-762, ACTS, 7-10 October 1997.

[49] B. Daneshrad, L. Cimini Jr., and M. Carloni, "Clustered-OFDM transmitter implementation," in Proceedings of IEEE International Symposium on Personal, Indoor, and Mobile Radio Communications (PIMRC'96), (Taipei, Taiwan), pp. 1064-1068, IEEE, 15-18 Octo* ber 1996.

[50] M. Okada, H. Nishijima, and S. Komaki, "A maximum likelihood decision based nonlinear distortion compensator for multicarrier modulated signals," IEICE Transactions on Communications, vol. E81B, no. 4, pp. 737-744, 1998.

[51] R. Dinis and A. Gusmao, "Performance evaluation of a multicarrier modulation technique allowing strongly nonlinear amplification," in Proceedings of ICC 1998, pp. 791-796, IEEE, 1998.

[52] T. Pollet, M. van Bladel, and M. Moeneclaey, "BER sensitivity of OFDM systems to carrier frequency offset and wiener phase noise," IEEE Transactions on Communications, vol. 43, pp. 191193, February/March/April 1995.

[53] H. Nikookar and R. Prasad, "On the sensitivity of multicarrier transmission over multipath channels to phase noise and frequency offset," in Proceedings of IEEE International Symposium on Personal, Indoor, and Mobile Radio Communications (PIMRC'96), (Taipei, Taiwan), pp. 68-72, IEEE, 15-18 October 1996.

[54] W. Warner and C. Leung, "OFDM/FM frame synchronization for mobile radio data communication," IEEE Transactions on Vehicular Technology, vol. 42, pp. 302-313, August 1993.

[55] H. Sari, G. Karam, and I. Jeanclaude, "Transmission techniques for digital terrestrial TV broadcasting," IEEE Communications Magazine, pp. 100-109, February 1995.

[56] P. Moose, "A technique for orthogonal frequency division multiplexing frequency offset correction," IEEE Transactions on Communications, vol. 42, pp. 2908-2914, October 1994.

[57] K. Brüninghaus and H. Rohling, "Verfahren zur Rahmensynchronisation in einem OFDM-System," in 3. OFDM Fachgespräch in Braunschweig, 1998.

[58] F. Daffara and O. Adami, "A new frequency detector for orthogona! multicarrier transmission techniques," in Proceedings of IEEE Vehicular Technology Conference (VTC'95), (Chicago, USA), pp. 804-809, IEEE, 15-28 July 1995.

[59] M. Sandell, J.-J. van de Beek, and P. Börjesson, "Timing and frequency synchronisation in OFDM systems using the cyclic prefix," in Proceedings of International Symposium on Synchronisation, (Essen, Germany), pp. 16-19, 14-15 December 1995.

[60] N. Yee, 1.-P. Linnartz, and G. Fettweis, "Multicarrier CDMA in indoor wireless radio networks," in PIMRC'93, pp. 109-113, 1993.

[61] A. Chouly, A. Brajal, and S. Jourdan, "Orthogonal multicarrier techniques applied to direct sequence spread spectrum CDMA systems," in Proceedings of the IEEE Global Telecommunications Conference 1993, (Houston, TX, USA), pp. 1723-1728, 29 November - 2 December 1993.

[62] G. Fettweis, A. Bahai, and K. Anvari, "On multi-carrier code division multiple access (MC-CDMA) modem design," in Proceedings of IEEE VTC '94, (Stockholm, Sweden), pp. 1670-1674, IEEE, 810 June 1994

[63] K. Fazel and L. Papke, "On the performance of convolutionallycoded CDMA/OFDM for mobile communication system," in PlMRC'93, pp. 468-472, 1993.

[64] R. Prasad and S. Hara, "Overview of multicarrier CDMA," IEEE Communications Magazine, pp. 126-133, December 1997.

[65] B.-J. Choi, E.-L. Kuan, and L. Hanzo, "Crest-factor study of MCCDMA and OFDM," in Proceeding of VTC'99 (Fall), vol. 1, (Amsterdam, Netherlands), pp. 233-237, IEEE, 19-22 September 1999.

[66] P. Höher, "TCM on frequency-selective land-mobile fading channels," in International Workshop on Digital Communications, (Titrenia, Italy), pp. 317-328, September 1991.

[67] J. Chow, J. Cioffi, and J. Bingham, "Equalizer training aigorithms for multicarrier modulation systems." in International Conference on Communications, (Geneva, Switzerland), pp. 761-765, IEEE, May 1993.

[68] S. Wilson, R. E. Khayata, and J. Cioffi, "16QAM Modulation with Orthogonal Frequency Division Multiplexing in a Rayleigh-Fading Environment," in Vehicular Technology Conference, vol. 3, (Stockholm, Sweden), pp. 1660-1664, IEEE, June 1994
[69] J.-J, van de Beek, O. Edfors, M Sandell, S. Wilson, and P. Börjesson, "On channel estimation in OFDM systems," in Proceedings of Vehicular Technology Conference, vol. 2, (Chicago, IL USA), pp. 815-819, IEEE, July 1995.

[70] O. Edfors, M. Sandell, J. van den Beek, S. K. Wilson, and P. Börjesson, "OFDM Channel Estimation by Singular Value Decomposition," in Proceedings of Vehicular Technology Conference, vol. 2, (Atlanta, GA USA), pp. 923-927, IEEE, April 28 - May 1 1996.

[71] P. Frenger and A. Svensson, "A Decision Directed Coherent Detector for OFDM" in Proceedings of Vehicular Technology Conference, vol. 3, (Atlanta, GA USA), pp. 1584-1588, IEEE, Apr 28 - May 1 1996.

[72] V. Mignone and A. Morello, "CD3-OFDM: A Novel Demodulation Scheme for Fixed and Mobile Receivers," IEEE Transactions on Communications, vol. 44, pp. 1144-1151, September 1996.

173] F. Tufvesson and T. Maseng, "Pilot Assisted Channel Estimation for OFDM in Mobile Cellular Systems," in Proceedings of Vehicular Technology Conference, vol. 3, (Phoenix, Arizona), pp. 1639-1643, IEEE, May 4-7 1997.

[74] P. Höher, S. Kaiser, and P. Robertson, "Two-dimensional pilotsymbol-aided channel estimation by Wiener filtering," in International Conference on Acoustics, Speech and Signal Processing, (Munich, Germany), pp. 1845-1848, IEEE, April 1997.

[75] P. Höher, S. Kaiser, and P. Robertson, "Pilot-symbol-aided channel estimation in time and frequency," in Proceedings of Global Telecommunications Conference: The Mini-Conf., (Phoenix, AZ), pp. 90-96, IEEE, November 1997.

[76] Y. Li, L. Cimini, and N. Sollenberger, "Robust Channel Estimation for OFDM Systems with Rapid Dispersive Fading Channels," IEEE Transactions on Communications, vol. 46, pp. 902-915, April 1998.

[77] O. Edfors, M. Sandell, J.-J. van den Beek, S. Wilson, and P. Böriesson, "OFDM Channel Estimation by Singular Value Decomposition," IEEE Transactions on Communications, vol. 46 pp. 931-939, April 1998.

178] F. Tufvesson, M. Faulkner, and T. Maseng, "Pre-Compensation for Rayleigh Fading Channels in Time Division Duplex OFDM Systems," in Proceedings of 6th International Workshop on Intelligen Signal Processing and Communications Systems, (Melbourne, Australia), pp. 57-33, IEEE, November 5-6 1998.

[79] M. Itami, M. Kuwabara, M. Yamashita, H. Ohta, and K. Itoh, "Equalization of Orthogonal Frequency Division Multiplexed Signal by Pilot Symbol Assisted Multipath Estimation," in Proceeding. of Global Telecommunications Conference, vol. 1, (Sydney, Australia), pp. 225-230, IEEE, November 8-12 1998.

[80] E. Al-Susa and R. Ormondroyd, "A Predictor-Based Decision Feedback Channe! Estimation Method for COFDM with High Resilience to Rapid Time-Variations," in Proceedings of Vehicular Technology Conference, vol. 1, (Amsterdam, Netherlands), pp. 273-278, IEEE, September 19-22 1999.

[81] B. Yang, K. Letaief, R. Cheng, and Z. Cao, "Robust and Improved Channel Estimation for OFDM Systems in Frequency Selective Fading Channets," in Proceedings of Global Telecommunications Conference, vol. 5, (Rio de Janejro, Brazil), pp. 2499-2503, IEEE, December 5-9 1999.

[82] Y. Li, "Pilot-Symbol-Aided Channel Estimation for OFDM in Wireless Systems," IEEE Transactions on Vehicular Technology, vol. 49 pp. 1207-1215, July 2000 .

[83] B. Yang, K. Letaief, R. Cheng, and Z. Cao, "Channel Estimation for OFDM Transmission in Multipath Fading Channels Based on Parametric Channel Modeling," IEEE Transactions on Communications, vol. 49, pp. 467-479, March 2001.

[84] S. Zhou and G. Giannakis, "Finite-Alphabet Based Channel Estimation for OFDM and Related Multicarrier Systems," IEEE Transactions on Communications, vol. 49, pp. 1402-1414, August 2001.

[85] X. Wang and K. Liu, "OFDM Channel Estimation Based on TimeFrequency Polynomial Model of Fading Multipath Channel," in Proceedings of Vehicular Technology Conference, vol. I, (Atlantic City, NJ USA), pp. 460-464, [EEE, October 7-11 2001.

[86] B. Yang, Z. Cao, and K. Letaief, "Analysis of Low-Complexity Windowed DFT-Based MMSE Channel Estimator for OFDM Systems," IEEE Transactions on Communications, vol. 49, pp. 1977-1987, November 2001.

[87] B. Lu and X. Wang, "Bayesian Blind Turbo Receiver for Coded OFDM Systems with Frequency Offset and Frequency-Selective Fading," IEEE Journal on Selected Areas in Communications, vol. 19, pp. 2516-2527, December 2001. 
[88] Y. Li and N. Sollenberger, "Clustered OFDM with Channel Estimation for High Rate Wireless Data," IEEE Transactions on Communications, vol. 49, pp. 2071-2076, December 2001.

[89] M. Morelli and U. Mengali, "A Comparison of Pilot-Aided Channel Estimation Methods for OFDM Systems," IEEE Transactions on Signal Processing, vol. 49, pp. 3065-3073, December 2001.

[90] M.-X. Chang and Y. Su, "Model-Based Channel Estimation for OFDM Signais in Rayleigh Fading," IEEE Transactions on Communications, vol. 50, pp. 540-544, April 2002.

[91] M. Necker and G. Stüber, "Totally Blind Channel Estimation for OFDM over Fast Varying Mobile Channels," in Proceedings of International Conference on Communications, (New York, NY USA), IEEE, April 28 - May 22002.

[92] B. Yang, Z. Cao, and K. Letaief, "Low Complexity Channel Estimator Based on Windowed DFT and Scalar Wiener Filter for OFDM Systems," in Proceedings of International Conference on Communications, vol. 6, (Helsinki, Finnland), pp. 1643-1647, IEEE, June 11-142001.

[93] J. Deller, J. Proakis, and J. Hansen, Discrete-Time Processing of Speech Signals. Macmillan Publishing Company, 1993.

[94] L. Hanzo, F. Somerville, and J. Woodard, Voice Compression and Communications. IEEE Press Wiley Inter-Science, 2001.

[95] A. Duel-Hallen, S. Hu, and H. Hallen, "Long Range Prediction of Fading Signals," IEEE Signal Processing Magazine, vol. 17, pp. 6275, May 2000.

[96] F. Tufvesson, Design of Wireless Communication Systems - Issues on Synchronization, Channel Estimation and Multi-Carrier Systems. Department of Applied Electronics, Lund University, Sweden, 2000

[97] W. Press, S. Teukolshy, W. Vetterling, and B. Flannery, Numerical Recipes in C. Cambridge University Press, 1992.

[98] T. Moon and W. Stirling, Mathematical Methods and Algorithms for Signal Processing. Prentice Hall, 2000

[99] Y. Li, N. Seshadri, and S. Ariyavisitakul, "Channel Estimation for OFDM Systems with Transmitter Diversity in Mobile Wireless Channets," IEEE Journal on Selected Areas in Communications, vol. 17, pp. 46!-471, March 1999.

[100] W. Jeon, K. Paik, and Y. Cho, "An Efficient Channel Estimation Technjque for OFDM Systems with Transtnitter Diversity," in Pro. ceedings of International Symposium on Personal, Indoor and Mo bile Radio Communications, vol. 2, (Hilton London Metropole Hotel, London, UK), pp. 1246-1250, IEEE, September 18-21 2000

[101] Y. Li, "Optimum Training Sequences for OFDM Systems with Multiple Transmit Antennas," in Proc. of Global Telecommunications Conference, vol. 3, (San Francisco, United States), pp. 1478-1482, IEEE, November 27 - December 12000.

[102] A. Mody and G. Stúber, "Parameter Estimation for OFDM with Transmit Receive Diversity," in Proceedings of Vehicular Technology Conference, vol. 2, (Rhodes, Greece), pp. 820-824, IEEE, May 6-9 2001 .

[103] Y. Gong and K. Letaief, "Low Rank Channel Estimation for SpaceTime Coded Wideband OFDM Systems," in Proceedings of Vehicular Technology Conference, vol. 2, (Atlantic City Convention Center, Atlantic City, NJ USA), pp. 772-776, IEEE, October 7-11 2001.

[104] W. Jeon, K. Paik, and Y. Cho, "Two-Dimensional MMSE Channel Estimation for OFDM Systerns with Transmitter Diversity," in Proceedings of Vehicular Technology Conference, vol. 3, (Atlantic City Convention Center, Atlantic City, NI USA), pp. 1682-1685, IEEE, October 7-11 2001

[105] F, Vook and T. Thomas, "MMSE Multi-User Channel Estimation for Broadband Wireless Communications," in Proceedings of Global Telecommunications Conference, vol. 1, (San Antonio, Texas, USA), pp. 470-474, IEEE, November 25-29 2001.

[106] Y. Xie and C. Georghiades, "An EM-based Channel Estimation Algorithm for OFDM with Transmitter Diversity," in Proceedings of Global Telecommunications Conference, vol. 2, (San Antonio, Texas, USA), pp. 871-875, IEEE, November 25-29 2001

[107] Y. Li, "Simplified Channel Estimation for OFDM Systems with Multiple Transmit Antennas," IEEE Transactions on Wireless Communications, vol. 1, pp. 67-75, January 2002.

[108] H. Bölcskei, R. Heath, and A. Paulraj, "Blind Channel Identification and Equalization in OFDM-Based Multi-Antenna Systems," IEEE Transactions on Signal Processing, vol. 50, pp. 96-109, January 2002 .
[109] H. Minn, D. Kim, and V. Bhargava, "A Reduced Complexity Channel Estimation for OFDM Systems with Transmit Diversity in Mobile Wireless Channels," IEEE Transactions on Wireless Communications, vol. 50, pp. 799-807, May 2002.

[110] S. Stimane, "Channel Estimation for HIPERLAN/2 with Transmitter Diversity," in International Conference on Communications, (New York, NY USA), IEEE, April 28 - May 2002.

[111] C. Komninakis, C. Fragouli, A. Sayed, and R. Wesel, "MultiInput Multi-Output Fading Channel Tracking and Equalization Using Kalman Estimation," IEEE Transactions on Signal Processing, vol. 50, pp. 1065-1076, May 2002.

[112] G. Foschini, "Layered Space-Time Architecture for Wireless Com munication in a Fading Environment when using Multi-Element Antennas"," Bell Labs Technical Journal, vol. Autumn, pp. 41-59, 1996.

[113] F. Vook and K. Baum, "Adaptive antennas for OFDM," in Proceedings of IEEE Vehicular Technology Conference (VTC'98), vol. 2. (Ottawa, Canada), pp. 608-610, IEEE, 18-21 May 1998

[114] X. Wang and H. Poor, "Robust Adaptive Array for Wireless Communications," IEEE Transactions on Communications, vol. 16 , pp. 1352-1366, October 1998.

[115] K.-K. Wong, R.-K. Cheng, K. Letaief, and R. Murch, "Adaptive Antennas at the Mobile and Base Station in an OFDM/TDMA System," in Proceedings of Global Telecommunications Conference, vol. i, (Sydney, Australia), pp. 183-190, IEEE, November 8-12 1998.

[116] Y. Li and N. Sollenberger, "Interference Suppression in OFDM Systems using Adaptive Antenna Arrays," in Proceedings of Global Telecommunications Conference, vol. 1, (Sydney, Australia), pp. 213-2 18, IEEE, November 8-12 1998.

[117] G. Golden, G. Foschini, R. Valenzuela, and P. Wolniansky, "Detection Algorithms and Initial Laboratory Results using V-BLAST Space-Time Communication Architecture," IEE Electronics Letters, vol. 35, pp. 14-16, January 1999.

[118] Y. Li and N. Sollenberger, "Adaptive Antenna Arrays for OFDM Systems with Cochannel Interference," IEEE Transactions on Communications, vol. 47, pp. 217-229, February 1999.

[119] P. Vandenameele, L. Van der Perre, M. Engels, and H. Man, "A nove class of uplink OFDM/SDMA algorithms for WLAN," in Proceedings of Global Telecommunications Conference - Globecom'99, vol. 1, (Rio de Janeiro, Brazil), pp. 6-10, IEEE, 5-9 December 1999.

[120] M. Speth, A. Senst, and H. Meyr, "Low complexity space-frequency MLSE for multi-user COFDM," in Proceedings of Global Telecommunications Conference - Globecom'99, vol. 1, (Rio de Janeiro, Brazil), pp. 2395-2399, IEEE, 5-9 December 1999.

[121] C. H. Sweatman, J. Thompson, B. Mulgrew, and P. Grant, “A Comparison of Detection Algorithms including BLAST for Wireless Communication using Multiple Antennas,": in Proceedings of International Symposium on Personal Indoor and Mobile Radio Communications, vol. 1, (Hilton London Metropole Hotel, London, UK), pp. 698-703, lEEE, September 18-21 2000.

[122] R. van Nee, A. van Zelst, and G. Awater, "Maximum Likelihood Decoding in a Space-Division Multiplexing System," in Proceedings of Vehicular Technology Conference, vol. ?, (Tokyo, Japan), pp. 6-10, IEEE, May 15-18 2000.

[123] G. Awater, A. van Zelst, and R. van Nee, "Reduced Complexity Space Division Multiplexing Receivers," in Proceedings of Vehicular Technology Conference, vol. 1, (Tokyo, Japan), pp. 11-15, IEEE, May 15-18 2000.

[124] A. van Zelst, R. van Nee, and G. Awater, "Space Division Multiplexing (SDM) for OFDM systems," in Proceedings of Vehicular Tech nology Conference, vol. 2, (Tokyo, Japan), pp. 1070-1074, IEEE May $15-182000$

[125] P. Vandenameele, L. V. D. Perre, M. Engels, B. Gyselinckx, and H. D. Man, "A Combined OFDM/SDMA Approach," IEEE Journal on Selected Areas in Communications, vol. 18, pp. 2312-2321, November 2000.

[126] X. Li, H. Huang, A. Lozano, and G. Foschini, "Reduced-Complexity Detection Algorithms for Systems Using Multi-Element Arrays." in Proc. of Global Telecommunications Conference, vol. 2, (San Francisco, United States), pp. 1072-1076, IEEE, November 27 - December 12000 .

[127] C. Degen, C. Walke, A. Lecomte, and B. Rembold, "Adaptive MIMO Techriques for the UTRA-TDD Mode," in Proceedings of Vehicular Technology Conference, vol. 1, (Rhodes, Greece), pp. 108-112, IEEE, May 6-9 2001. 
[128] X. Zhu and R. Murch, "Multi-Input Multi-Output Maximum Likelihood Detection for a Wireless System," in Proceedings of Vehicular Technology Conference, vol. 1, (Rhodes, Greece), pp. 137-141, IEEE, May 6-9 2001.

[129] J. Li, K. Letaief, R. Cheng, and Z. Cao, "Joint Adaptive Power Control and Detection in OFDM/SDMA Wireless LANs," in Proceedings of Vehicular Technology Conference, vol. 1, (Rhodes, Greece), pp. 746-750, IEEE, May 6-9 2001.

[130] F. Rashid-Farrokhi, K. Liu, and L. Tassiulas, "Transmit Beamforming and Power Control for Cellular Wireless Systems," IEEE Journal on Selected Areas in Communications, vol. 16, pp. 1437-1450, October 1998.

[131] A. van Zelst, R. van Nee, and G. Awater, "Turbo-BLAST and its Performance," in Proceedings of Vehicular Technology Conference, vol. 2, (Rhodes, Greece), pp. 1282-1286, IEEE, May 6-9 2001.

[132] A. Benjebbour, H. Murata, and S. Yoshida, "Performance of Iterative Successive Detection Algorithm with Space-Time Transmission," in Proceedings of Vehicular Technology Conference, vol, 2, (Rhodes, Greece), pp. 1287-1291, IEEE, May 6-9 2001.

[133] M. Sellathurai and S. Haykin, "A Simplified Diagonal BLAST Architecture with Iterative Parallel-Interference Cancellation Receivers," in Proceedings of International Conference on Communications, vol. 10, (Helsinki, Finnland), pp, 3067-3071, IEEE, June $11-142001$.

[134] A. Bhargave, R. Figueiredo, and T. Eltoft, "A Detection Algorithm for the V-BLAST System," in Proceedings of Global Telecommunications Conference, vol. 1, (San Antonio, Texas, USA), pp. 494 498, IEEE, November 25-29 2001

[135] S. Thoen, L. Deneire, L. V. D. Perre, and M. Engels, "Constrained Least Squares Detector for OFDM/SDMA-based Wireless Networks," in Proceedings of Global Telecommunications Conference, vol. 2, (San Antonio, Texas, USA), pp. 866-870, IEEE, November 25.29 2001

[136] Y. Li and Z.-Q. Luo, "Parallel Detection for V-BLAST System," in Proceedings of International Conference on Communications, (New York, NY USA), IEEE, A pril 28 - May 2002.

[137] Y. Li and N. Sollenberger, "Interference suppression in OFDM systems using adaptive antenna arrays," in Proceeding of Globecom '98, (Sydney, Australia), pp. 213-218, IEEE, 8-12 November 1998.

[138] Y. Li and N. Sollenberger, "Adaptive antenna arrays for OFDM systems with cochannel interference," IEEE Transactions on Communicutions, vol. 47, pp. 217-229, February 1999.

[139] Y. Li, L. Cimini, and N. Sollenberger, "Robust channel estimation for OFDM systems with rapid dispersive fading channels," IEEE Transactions on Communications, vol. 46, pp. 902-915, Aprif 1998 ,

[140] C. Kim, S. Choi, and Y. Cho, "Adaptive beamforming for an OFDM sytem," in Proceeding of VTC'99 (Spring), (Houston, TX, USA), IEEE, 16-20 May 1999.

[141] L. Lin, L. Cimini Jr., and J.-I. Chuang, "Turbo codes for OFDM with antenna diversity," in Proceeding of VTC'g9 (Spring), (Houston, TX, USA), IEEE, 16-20 May 1999.

[142] M. Münster, T. Keller, and L. Hanzo, "Co-channel interference suppression assisted adaptive OFDM in interference limited environments," in Proceeding of VTC'99 (Fall), vol. 1, (Amsterdarn, Netherlands), pp. 284-288, IEEE, 19-22 September 1999.

[143] S. Verdu, Multiuser Detection. Cambridge University Press, 1998.

[144] J. Litva and T.-Y. Lo, Digital Beamforming in Wireless Communications. London: Artech House Publishers, 1996.

[145] P. Vandenameele, L. Van der Perre, M. Engels, B. Gyselinckx, and H. Man, "A novel class of uplink OFDM/SDMA algorithms: A statistical performance analysis," in Proceedings of Vehicular Technology Conference, vol. 1, (Amsterdam, Netherlands), pp. 324-328, IEEE, 19-22 September 1999

[146] ETSI, Digital Audio Broadcasting (DAB), 2nd ed., May 1997. ETS 300401.

[147] ETSI, Digital Video Broadcasting (DVB); Framing structure, channel coding and modulation for digital terrestrial television, August 1997. EN 300744 V1.1.2.

[148] P. Chow, J. Tu, and J, Cioffi, "A discrete multitone transceiver system for HDSL applications," IEEE journal on selected areas in communications, vol. 9, pp. 895-908, August 1991.

[149] P. Chow, J. Tu, and J. Cioffi, "Performance evaluation of a multichannel transceiver system for ADSL and VHDSL services," IEEE journal on selected areas in communications, vol, 9, pp. 909-919, August 1991.
[150] K. Sistanizadeh, P. Chow, and J. Cioff, "Multi-tone transmission for asymmetric digita! subscriber lines (ADSL)," in Proceedings of ICC'93, pp. 756-760, IEEE, 1993.

[151] ANSI, ANSI/TIE1.4/94-007, Asymmetric Digilal Subscriber Line (ADSL) Metallic Interface., August 1997.

[152] A. Burr and P. Brown, "Application of OFDM to powerline telecommunications," in 3rd International Symposium On Power-Line Communications, (Lancaster, UK), 30 March - 1 April 1999.

[153] M. Deinzer and M. Stoger, "Integrated PLC-modern based on OFDM," in 3rd International Symposium On Power-Line Communications, (Lancaster, UK), 30 March - 1 April 1999.

[154] R. Prasad and H. Harada, "A novel OFDM based wireless ATM system for future broadband multimedia communications," in Proceeding of ACTS Mobile Communication Summit '97, (Aalborg, Denmark), pp. 757-762, ACTS, 7-10 October 1997.

[155] C. Ciotti and J. Borowski, "The AC006 MEDIAN project overview and state-of-the-art," in Proc. ACTS Summit '96, (Granada, Spain), pp. 362-367, 27-29 November 1996.

[156] J. Borowski, S. Zeisberg, J. Hübner, K. Koora, E. Bogenfeld, and B. Kull, "Performance of OFDM and comparable single carrier system in MEDIAN demonstrator $60 \mathrm{GHz}$ channel," in Proceeding of ACTS Mobile Communication Summit '97, (Aalborg, Denmark), pp. 653-658, ACTS, 7-10 October 1997.

[157] M. D. Benedetto, P. Mandarini, and L. Piazzo, "Effects of a mismatch in the in-phase and in-quadrature paths, and of phase noise, in QDCPSK-OFDM modems," in Proceeding of ACTS Mobile Communication Summit '97, (Aalborg, Denmark), pp. 769-774, ACTS, 7-10 October 1997.

[158] T. Rautio, M. Pietikainen, J. Niemi, J. Rautio, K. Rautiola, and A. Mammela, "Architecture and implementation of the $150 \mathrm{Mbit} / \mathrm{s}$ OFDM modem (invited paper)," in IEEE Benelux Joint Chapter on Communications and Vehicular Technology, 6th Symposium on Vehicular Technology and Communications, (Helsinki, Finland), p. 11, 12-13 October 1998.

[159] J. Ala-Laurila and G. Awater, "The magic WAND - wireless ATM network demondtrator system," in Proceeding of ACTS Mobile Communication Summit '97, (Aalborg, Denmark), pp. 356-362, ACTS, 7-10 October 1997.

[160] J. Aldis, E. Busking, T、 Kleijne, R. Kopmeiners, R. yan Nee, R. Mann-Pelz, and T. Mark, "Magic into reality, building the WAND modem," in Proceeding of ACTS Mobile Communication Summit '97. (Aalborg, Denmark), pp. 775-780, ACTS, 7-10 October 1997.

[161] E. Hallmann and H. Rohling, "OFDM-Vorsch]äge für UMTS," in 3. OFDM Fachgespräch in Braunschweig, 1998.

[162] "Universal mobile telecommunications system (UMTS); UMTS terrestrial radio access (UTRA); concept evaluation," tech. rep., ETSI, 1997. TR 101146.

[163] T. Eng and L. Milstein, "Coherent DS-CDMA performance in Nakagami multipath fading," IEEE Transactions on Communications, vol. 43, pp. 1134-1143, Feb./Mar./Apr. 1995.

[164] M. Nakagami, "The $m$-distribution-a general formula of intensity distribution of fading," Statistical Methods in Radio Wave Propagation, 1960. W.C. Hoffman, ed., New York: Pergamon.

[165] M. K. Simon and M. S. Alouini, Digital Communication over Fading Channels: A Unified Approach to Performance Analysis. John Wiley \& Sons, Inc., 2000. ISBN 0471317799.

[166] S. Watanabe, T. Sato, M. Sengoku, and T. Abe, "Bit error rate evaluation of delay time control scheme for reverse channel on orthogonal coding multi-carrier CDMA," IEICE Transaction on Fundamentals of Electronics Communications and Computer Sciences, vol. E80-A pp. 1226-1232, July 1997.

[167] P. Jung and J. Blanz, "Joint detection with coherent receiver antenna diversity in CDMA mobile radio systems," IEEE Transactions on Vehicular Technology, vol. 44, pp. 76-88, February 1995.

[168] T. Liew and L. Hanzo, "Space-time block codes and concatenated channel codes for wireless communications," Proceedings of the IEEE, vol. 90, pp. 187-219, February 2002.

[169] J. F. Hayes, "Adaptive feedback communications," IEEE Transactions on Communication Technology, vol. 16, no, 1, pp, 29-34, 1968.

[170] W. T. Webb and R. Steele, "Variable rate QAM for mobile radio," IEEE Transactions on Communications, vol. 43, no. 7, pp. 2223$2230,1995$.

[171] T. Keller and L. Hanzo, "Adaptive modulation technique for duplex OFDM transmission," IEEE Transactions on Vehicular Technology, vol. 49, pp. 1893-1906, September 2000. 
[172] T. Keller and L. Hanzo, "Adaptive multicarrier modulation: A convenient framework for time-frequency processing in wireless communications," Proceedings of the IEEE, vol. 88, pp. 611-642, May 2000.

[173] T. Keller, T. H. Liew, and L. Hanzo, "Adaptive redundant residue number system coded multicarrier modulation," IEEE Journal on Selected Areas in Communications, vol, 18, pp. 1292-2301, November 2000.

[174] T. Keller, M. Münster, and L. Hanzo, "A turbo-coded burst-by-burst adaptive wide-band speech transceiver," IEEE Journal on Selected Areas in Communications, vol, 18, pp. 2363-2372, November 2000.

[175] C. Berrou and A. Glavieux, "Near optimum error correcting coding and decoding: turbo codes," IEEE Transactions on Communica* tions, vol. 44, pp. 1261-1271, October 1996.

[176] J. Torrance and L. Hanzo, "Optimisation of switching levels for adaptive modulation in a slow Rayleigh fading channel," Electronics Letters, vol. 32, pp. 1167-1169, 20 June 1996.

[177] B-J. Choi and L. Hanzo, "Performance Analysis of Rake-Receiver Assisted Adaptive QAM using Antenna Diversity over Frequency Selective Rayleigh Channels," IEEE Transactions on Vehicular Technology, vol. 52, pp. 536-560, May 2003.

[178] B. J. Choi, M. Münster, L. L. Yang, and L. Hanzo, "Performance of Rake receiver assisted adaptive-modulation based CDMA over frequency selective slow Rayleigh fading channel," Electronics Letters, vol. 37, pp. 247-249, February 2001.

[179] S. Alamouti, "A Simple Transmit Diversity Technique for Wireless Communications," IEEE Journal on Selected Areas in Communications, vot. 16, pp. 1451-1458, October 1998.

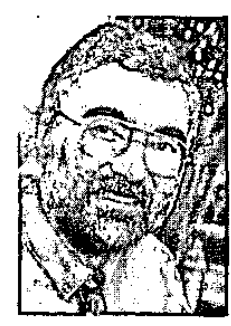

Lajos Hanzo, Fellow of the Royal Academy of Engineering, received his degree in electronics in 1976 and his doctorate in 1983 from the Technical University of Budapest, Hungary. In 2004 he was awarded the Doctor of Sciences (DSc) de. gree by the University of Southampton, UK. During his career in telecommunications he has held various research and academic posts in Hungary, Germany and the UK. Since 1986 he has been with the School of Electronics and Computer Science, University of Southampton, UK, where he holds the Chair in Telecommunications. He coauthored 10 books totalling 8000 pages on mobile radio communications, published in excess of 500 research papers, organised and chaired conference sessions, presented overview lectures and has been awarded a number of distinctions. Currently he heads an academic research team, working on a range of research projects in the field of wireless multimedia communications sponsored by industry, the Engineering and Physical Sciences Research Council (EPSRC) UK, the European IST Programme and the Mobile Virtual Centre of Excellence (VCE), UK. He is an enthusiastic supporter of industrial and academic liaison and he offers a range of industrial courses. Lajos is also an IEEE Distinguished Lecturer of both the Communications as well as the Vehicular Technology Society and a Fellow of both the IEE and IEEE. For further information on research in progress and associated publications please refer to http://www-mobile.ecs.soton.ac.uk

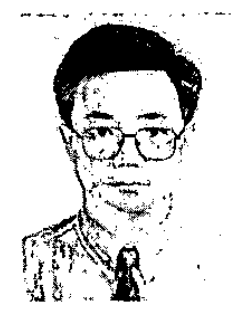

Lje-Liang Yang received his M.Eng, Ph.D. degrees in communications and electronics from Northern Jiaotong University, Beijing, China in 1991 and 1997, respectively, and his B.Eng. degree in communications engineering from Shanghai TieDao University, Shanghai, China in 1988. Since December 1997, he has been with the Communications Research Group at the Department of Electronics and Computer Science of University of Southampton, UK, where he held various research posts as a visiting postdoctoral research fellow, research fellow and senior research fellow. Currently holds an academic post as a lecturer. From June 1997 to December 1997 he was a visiting scientist of the IREE, Academy of Sciences of the Czech Republic. He has been invoived in a number of projects funded by the National Sciences Foundations of China, the Grant Agency of the Czech Republic, the Engineering and Physical Sciences Research Council (EPSRC) of UK and the European Union. His research has covered a wide range of areas in communications, which include data network and security, intelligent wireless networking, error control coding, modulation and demodulation, spread-spectrum communications and multiuser detection, pseudo-noise (PN) code synchronisation, smart antennas, adaptive wireless systems, as well as wideband, broadband and ultrawide-band code-division multipleaccess (CDMA) for advanced wireless mobile communication systems. He has published over 90 papers in various journals and conference proceedings. He is a senior member of the IEEE.

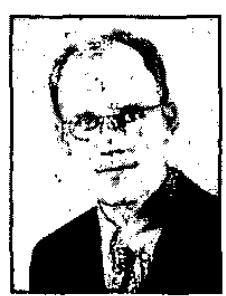

Matthias Münster was awared the Dipl. Ing. degree by the RWTH Aachen, Germany and after graduation he embarked on postgraduate research at the University of Southampton, where he completed his $\mathrm{PhD}$ in mobile communications on 2002. His areas of interest include adaptive multiuser OFDM transmission, wideband channel estimation, multiuser detection and a range of related signal processing aspects. During his $\mathrm{PhD}$ research he contributed over a dozen various research papers and following the completion of his thesis he returned to his native Germany, where he is currently involved in the development of sophisticated signal processing algorithms.

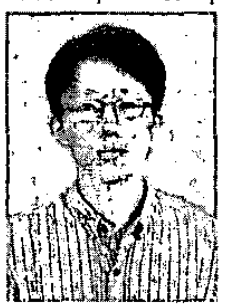

Byoung-Jo Choi received his BSc and MSc degrees in Electrical Engineering from KAIST, Korea, in 1990 and 1992, respectively. He has been working for LG Electronics, Korea, since January 1992, where he was involved in developing the KoreaSat monitoring system, Digital DBS transmission system and W-CDMA based Wireless Local Loop (WLL) system. He was awarded the $\mathrm{PhD}$ degree in Mobile Communications at the University of Southampton, UK, where he was a postdoctoral research assistant from 2001 to 2002 . He is a recipient of the British Chevening Scholarship awarded by the British Council, UK. His current research interests are related to mobile communication systems design with emphasis on adaptive modulation aided OFDM, MC-CDMA and W-CDMA. 